\title{
Correlation between liver cancer occurrence and gene expression profiles in rat liver tissue
}

\author{
C.S. Xu ${ }^{1,2}$, G.P. Wang ${ }^{1}$, L.X. Zhang ${ }^{2}$, C.F. Chang ${ }^{2}$, J. Zhi ${ }^{1}$ and Y.P. Hao ${ }^{1}$ \\ ${ }^{1}$ College of Life Sciences, Henan Normal University, Xinxiang, \\ Henan Province, China \\ ${ }^{2}$ Key Laboratory for Cell Differentiation Regulation, Xinxiang, \\ Henan Province, China \\ Corresponding author: C.S. Xu \\ E-mail: xucs@x263.net
}

Genet. Mol. Res. 10 (4): 3480-3513 (2011)

Received January 31, 2011

Accepted September 27, 2011

Published December 14, 2011

DOI http://dx.doi.org/10.4238/2011.December.14.3

\begin{abstract}
Liver cancer (LC) is generally characterized by malignant cell proliferation and growth; it normally develops in stages that progress from non-specific injury of the liver to liver fibrosis, liver cirrhosis, dysplasia nodules, and liver carcinoma. We used a rat model of diethylnitrosamine (DENA)-induced LC; a Rat Genome 230 2.0 Array was used to detect gene expression profile of liver tissues from male rats $5,8,12,16$, and 18 weeks following the beginning of DENA-induced LC. We found 909 known genes, including 637 upregulated, 270 down-regulated, and two up/down-regulated genes, that were significantly changed in expression. Among them, 108 genes were expressed at the 5th, 213 at the 8 th, 516 at the 12 th, 698 at the 16th, and 506 at the 18th week of DENA-induced LC. Methods in bioinformatics and systems biology were applied to explore the correlation between the gene expression profile of rat liver tissue and liver cancer occurrence at the transcriptional level; 23 physiological activities were found to be associated with LC. Among these, eight physiological activities, including stimulus response, inflammation and immune response, oxidative reduction, cell proliferation, differentiation, migration, adhesion, and angiogenesis were increased, implying that
\end{abstract}


they could play important roles in the occurrence and development of LC. In addition, carbohydrate, lipid, and organic acid metabolism were decreased, suggesting that liver injury induced by a carcinogenic agent has a negative effect on the metabolism of fundamental substances.

Key words: Liver cancer; Gene expression profile; Systems biology; Physiological activity

\section{INTRODUCTION}

The liver is the largest digestive gland in the human body, and carries out a number of complex functions which are essential for life. Therefore, liver diseases are considered as a great threat to humans. Generally, primary liver cancer (LC) is one of the most common malignancies in Asia, especially in China. At present, the mechanism of liver carcinogenesis and treatment of liver cancer are poorly understood, but high-throughput microarray has emerged as a highly efficient analysis of liver function abnormalities associated with gene expression profiles. Meanwhile, hepatocarcinogenesis is a long-term, multistep process, and associated with changes in gene expression profiles. For example, Wurmbach et al. identified a group of gene markers for tracking the progression of hepatitis $\mathrm{C}$ virus (HCV)-induced liver carcinogenesis (Wurmbach et al., 2007) by utilizing high-density oligonucleotide microarrays. Additionally, Liu et al. found expression of a total of 694 genes, especially the inflammation response, immune response, and oxidative stress metabolism-related genes, was significantly changed during the development of diethylnitrosamine (DENA)-induced LC (Liu et al., 2009). The above studies could help researchers to explore the pathogenesis of hepatic cancer at the molecular level.

LC is characterized by malignant cell proliferation and growth, and the occurrence of LC covered the stages of non-specific injury of liver, liver fibrosis, liver cirrhosis, dysplasia nodules and liver carcinoma (Liu et al., 2009). According to the Edmonson grading system, the process of DENA-induced LC is divided into five phases: start-up period (1-5 weeks), interval phase (6-8 weeks), early phase (9-12 weeks), middle phase (13-16 weeks), late phase (17-20 weeks) (Edmondson and Steiner, 1954). In this study, a rat model of DENA-induced liver cancer was established, and Rat Genome 2302.0 Array, consisting of 25,020 genes, was used to detect gene expression profile of liver tissues from male rats following 5, 8, 12, 16, and 18 weeks of DENA induction. The goal of this study was to explore the correlation between gene expression profile of rat livers and the occurrence and progression of liver cancer at transcriptional level. These data provide useful information on the global gene expression changes due to DENA administration and offer important insights into the mechanisms of liver cancer.

\section{MATERIAL AND METHODS}

\section{Preparation of rat model of liver cancer}

Adult healthy male Sprague-Dawley rats, each weighing $210 \pm 20 \mathrm{~g}$, were supplied by the Experimental Animal Center of Henan Normal University, and were housed in a controlled temperature room $\left(22^{\circ} \pm 1^{\circ} \mathrm{C}\right.$ ) with a $12: 12 \mathrm{~h}$ light: dark cycle (light period 6:00 to 18:00). All rats were fed with standard rodent chow diet and allowed free access to distilled 
water. A total of 36 male rats were randomly divided into a control group containing 6 rats and a diethylnitrosamine (DENA)-induced group containing 30 rats. Rats in the DENA group underwent intragastric administration of DENA $(7 \mathrm{mg} / 100 \mathrm{~g})$ once a week, consecutively for 20 weeks. Six rats were anesthetized by ether and sacrificed by cervical dislocation at the end of $0,5,8,12,16$ and 18 weeks after DENA-treatment, respectively. The procured livers were immediately washed three times in $0.01 \mathrm{M}$ PBS at $4^{\circ} \mathrm{C}$. For each rat, approximately $100-200$ $\mathrm{mg}$ liver tissues were taken from the middle parts of the right lobe on ice and stored at $-80^{\circ} \mathrm{C}$ until use. All the handling procedures were carried out in accordance with the current Animal Protection Law of China.

\section{Histopathological detection of liver tissues from a rat model of DENA-induced liver cancer}

Small cuboids of approximately $5 \times 5 \mathrm{~mm} \times(2-3) \mathrm{mm}$ from the right lobe of the liver were fixed with $10 \%$ neutral-buffered formalin for $24 \mathrm{~h}$ and washed with tap water for $24 \mathrm{~h}$. Then they were routinely dehydrated with a graded series of ethanol, cleared in xylene, embedded in paraffin, sectioned at $5 \mu \mathrm{m}$ thickness. Afterwards, the slices were stained with hematoxylin for $3 \mathrm{~min}$, immerged in ammonia water $(\mathrm{pH} 8.0)$ for $30 \mathrm{~s}$, and counterstained with $0.5 \%$ eosin for $5 \mathrm{~min}$. Finally, they were dehydrated by gradient ethanol, cleared in xylene and sealed with neutral gum. Histopathologic examinations of the liver sections were conducted by a pathologist and peer-reviewed.

\section{Rat Genome 230 2.0 Microarray detection}

Total RNA was extracted according to the manual of Trizol reagent (Invitrogen Corporation, Carlsbad, USA) and purified following the RNeasy mini protocol (Qiagen Inc., Valencia, USA). The quality of total RNA was assessed by optical density measurement at $260 / 280 \mathrm{~nm}$ and agarose electrophoresis $(180 \mathrm{~V}, 0.5 \mathrm{~h})$. It was regarded as a qualified sample, when 28S RNA to 18S RNA was equal to 2:1. T7-oligo dT(24) (Keck Foundation, New Haven, USA) SuperScript II RT (Invitrogen Corporation) and $5 \mu \mathrm{g}$ total RNA was used to synthesize the first strand of cDNA. The second strand was synthesized using the Affymetrix cDNA single-stranded cDNA synthesis kit. The $12 \mu \mathrm{L}$ purified cDNA and the reagents in the GeneChip ${ }^{\circledR}$ in vitro Transcript Labeling Kit (ENZO Biochemical, New York, USA) were used to synthesize biotin-labeled cRNA. The labeled cRNA was purified using the RNeasy Mini Kit columns (Qiagen). $15 \mu \mathrm{L}$ cRNA $(1 \mu \mathrm{g} / \mu \mathrm{L})$ was incubated with $6 \mu \mathrm{L} 5 \mathrm{X}$ fragmentation buffer and $9 \mu \mathrm{L}$ RNase free water for $35 \mathrm{~min}$ at $94^{\circ} \mathrm{C}$, and digested into 35-200 bp cRNA fragments. The prehybridized Rat Genome 2302.0 Array was put into a hybridization buffer, and the hybridization was at $45^{\circ} \mathrm{C}$ in a hybridization oven (Affymetrix) at $60 \mathrm{rpm}$ for $16 \mathrm{~h}$. The hybridized arrays were washed by wash buffer, and stained in GeneChip ${ }^{\circledR}$ Fluidics Station 450 (Affymetrix). Then the arrays were scanned and imaged with a GeneChip ${ }^{\circledR}$ Scanner 3000 (Affymetrix) (Guo and $\mathrm{Xu}, 2008$; Xu and Chang, 2008).

\section{Identification of rat LC-related genes}

The GCOS 2.0 software (Affymetrix) was used to evaluate the images showing gene 
expression abundance generated by Rat Genome 2302.0 Array. The data for each microarray were normalized by scaling all signals to a target intensity of 500. Each probe set used in the Affymetrix GeneChip ${ }^{\circledR}$ produced a detection call, with $\mathrm{P}$ (present call, requiring a $\mathrm{P}$ value $<0.05$ ) indicating good quality, $\mathrm{M}$ (marginal call, requiring a $0.05<\mathrm{P}$ value $<0.065$ ) indicating intermediate quality and $\mathrm{A}$ (absent call with a $\mathrm{p}$ value $>0.065$ ) indicating relatively low reliability. Therefore, probe sets that resulted in A calls in the compared groups were removed to filter false positives. Next, fold change (the ratio of the normalized signal value of LC groups at each time point to that of the non-control (NC) group) and the Student t-test performance were applied to select the differentially expressed genes using a fold change threshold of 3.0fold and a $\mathrm{P}<0.05$ to indicate significance. e.g., the gene with $\geq 3$-fold higher expression than the NC group was regarded as up-regulation; the gene with $\geq 3$-fold lower expression than the NC group, as down-regulation; the gene with 0.33-2.99 fold, as an insignificantly expressed gene. To minimize the technical errors from microarray analysis, the average value of three independent detections by Rat Genome 2302.0 Array was considered as a reliable value. The coefficients of variation for three technical repeats of each gene were below $6 \%$. The genes expressed significantly in any one of weeks were considered as rat LC-related genes.

\section{Quantitative real-time RT-PCR}

The primers were designed with the Primer Express 2.0 software according to mRNA sequences of nine target genes trim24, mgmt, spink3, myc, spp1, ggt1, ccnd1, alpl, cypla1, and one internal control $\beta$-actin, and synthesized by Shanghai Generay Biotech Co., Ltd. (Table 1). Prior to RT, contaminating genomic DNA was removed by Dnase I (Promega, Mandison, USA). Total RNA ( 2 ug) was reverse-transcribed using random primers and Reverse Transcription Kit (Promega). First-strand cDNA samples were subjected to quantitative PCR amplification by using SYBR ${ }^{\circledR}$ Green I on the Rotor-Gene 3000A (Corbett Robotics, Brisbane, Australia). All of the PCR cycling conditions were modified to $95^{\circ} \mathrm{C}$ for $2 \mathrm{~min}$, followed by 40 cycles of $95^{\circ} \mathrm{C}$ for $15 \mathrm{~s}, 60^{\circ} \mathrm{C}$ for $15 \mathrm{~s}$, and $72^{\circ} \mathrm{C}$ for $30 \mathrm{~s}$. Each sample was analyzed in triplicate. Standard curves were generated from five repeated ten-fold serial dilutions of cDNA, and the copy numbers of target genes in each milliliter of the sample were calculated according to their corresponding standard curves (Wang and $\mathrm{Xu}, 2010$ ).

\section{Relevance analysis of gene synergy to physiological activity}

According to the classifications of physiological activities supported from gene oncology (GO) (www.geneontology.org), gene expression abundance detected by Rat Genome 2302.0 chip in rat model of LC, and functions and interactions of genes curated from ResNet Core1.2 database which is built-in the Pathway Studio 7.0 software, the multivariate statistical-supporting mathematical model of Wang et al. (Vera and Wolkenhauer, 2008; Wang et al., 2009) was applied to measures gene synergy collaborated by the related genes with time series analysis (McGuigan, 2006) and correlation analysis (Chen et al., 2010):

$$
\mathrm{E}_{\mathrm{t}}=\frac{\sum_{\mathrm{i}=1}^{\mathrm{n}} \sum_{\mathrm{k}=1}^{\mathrm{n}}\left[\left(\mathrm{X}_{\mathrm{i}}^{(\mathrm{t})}+\mathrm{X}_{\mathrm{k}}^{(\mathrm{t})}\right) * \mathrm{r}_{\mathrm{ik}}\right]}{\mathrm{n}(\mathrm{n}+1)}
$$


where $E$ describes the synergy value of genes participating in a physiological process, and $t$ represents a certain time point. $r_{i k}$ means correlation coefficient of genes $i$ and $k, X_{i}^{(t)}$ and $X_{k}^{(t)}$ expression abundances of genes $i$ and $k$ at a certain time point, and $n$ shows the total number of genes in a certain physiological process. The synergy value of genes participating in a physiological activity at a certain time point in DENA-induced LC group $(E)$ was significantly greater than the synergy value in $\mathrm{NC}$ group $\left(E_{c}\right)$, meaning that the physiological activity in LC at this time point is more elevated than in control. When $E_{t}$ is less than $E_{c}$, it means that the physiological activity in LC at this time point is weaker than in control, and when $E_{t}$ has no remarkable difference to $E_{c}$, it means that the physiological activities in both LC and NC group are comparable.

\begin{tabular}{|c|c|c|c|}
\hline Genes & Accession numbers & Primer sequences & Amplified products \\
\hline $\operatorname{trim} 24$ & NM_001044266 & $\begin{array}{l}\text { FP: 5'-CAGTGGGAGGGTCTTACAATC-3' } \\
\text { RP: 5'-CTGGCCAGGGTCTACACTTG-3' }\end{array}$ & $107 \mathrm{bp}$ \\
\hline$m g m t$ & NM_012861 & $\begin{array}{l}\text { FP: 5'-GAAGCCTATTTCCACGAACC-3' } \\
\text { RP: 5'-TCCATAACACCTGTCTGGTGAA-3' }\end{array}$ & $103 \mathrm{bp}$ \\
\hline spink3 & NM_012674 & $\begin{array}{l}\text { FP: 5'-CACCCTGCACAGTTCGTC-3' } \\
\text { RP: 5'-AGGGCAATTAGGCGTTTT-3' }\end{array}$ & $143 \mathrm{bp}$ \\
\hline myc & NM_012603 & $\begin{array}{l}\text { FP: 5'-GAGGAGAAACGAGCTGAAGCG-3' } \\
\text { RP: 5'-TGAACGGACAGGATGTAGGC-3' }\end{array}$ & $126 \mathrm{bp}$ \\
\hline sppl & NM_012881 & $\begin{array}{l}\text { FP: 5'-TGATGACGACGACGATGACGATGG-3' } \\
\text { RP: 5'-ACGCTGGGCAACTGGGATGACCTT-3' }\end{array}$ & $325 \mathrm{bp}$ \\
\hline ggtl & NM_053840 & $\begin{array}{l}\text { FP: 5'-TCTTCCAACCCAGCATCCAA-3' } \\
\text { RP: 5'-CACAAAGCAGGTGTCTTCTCAA-3' }\end{array}$ & $109 \mathrm{bp}$ \\
\hline ccndl 1 & NM_171992 & $\begin{array}{l}\text { FP: 5'-CCTGACTGCCGAGAAGTTGTGC-3' } \\
\text { RP: 5'-TGGAGGGTGGGTTGGAAATGAA-3' }\end{array}$ & $251 \mathrm{bp}$ \\
\hline alpl & NM_013059 & $\begin{array}{l}\text { FP: 5'-CATCGGACCCTGCCTTACCA-3' } \\
\text { RP: 5'-CGTGTCTCCTCGCCCGTGTT-3' }\end{array}$ & $231 \mathrm{bp}$ \\
\hline cyplal & NM_012540 & $\begin{array}{l}\text { FP: 5'-AGGACAGGAGGCTGGACGAGA-3' } \\
\text { RP: 5'-ATGGTGAATGGGACAAAGGAT-3' }\end{array}$ & $289 \mathrm{bp}$ \\
\hline$\beta$-actin & NM_031144 & $\begin{array}{l}\text { FP: 5'-CATCCGTAAAGACCTCTATGCCAACA-3' } \\
\text { RP: 5'-GTGCTAGGAGCCAGGGCAGTAATCT-3' }\end{array}$ & $109 \mathrm{bp}$ \\
\hline
\end{tabular}

$\mathrm{FP}=$ forward primer; $\mathrm{RP}=$ reverse primer.

\section{RESULTS}

\section{Histopathological changes of liver tissues during the occurrence and progression of rat liver cancer}

For rat normal livers, the structure of hepatic lobes was clear, with blood filled in central vein, orderly arranged hepatocytes in cords radiating from the central vein, and integrated hepatic sinuses. The hepatocytes were multi-face box-shaped, with one or two dark blue nuclei located in the cell centre and clear nucleolus (Figure 1A). In the 5th week of rat liver cancer, several hepatocytes were observed with hydropic degeneration though the structure of hepatic lobules was still intact (Figure 1B). In the 8th week, the structure of hepatic lobules was damaged, basophilic degeneration or hydropic degeneration of hepatocytes in some areas clearly visible, and hepatocytes began to proliferate (Figure 1C). In the 12th week, typical false lobules emerged with significant swelling of hepatocytes and proliferation of hepatocytes (Figure 1D). During the elongation of DEN-induction time, we found hepatocytes in the nodules 
were obviously swollen, and hyperplasic nodules remarkably squeezed the surrounding ones (Figure 1E). At the 18th week of liver cancer, hepatocyte necrosis was severe with a large and congestive cavity $(\square)$ in each cell (Figure 1F).
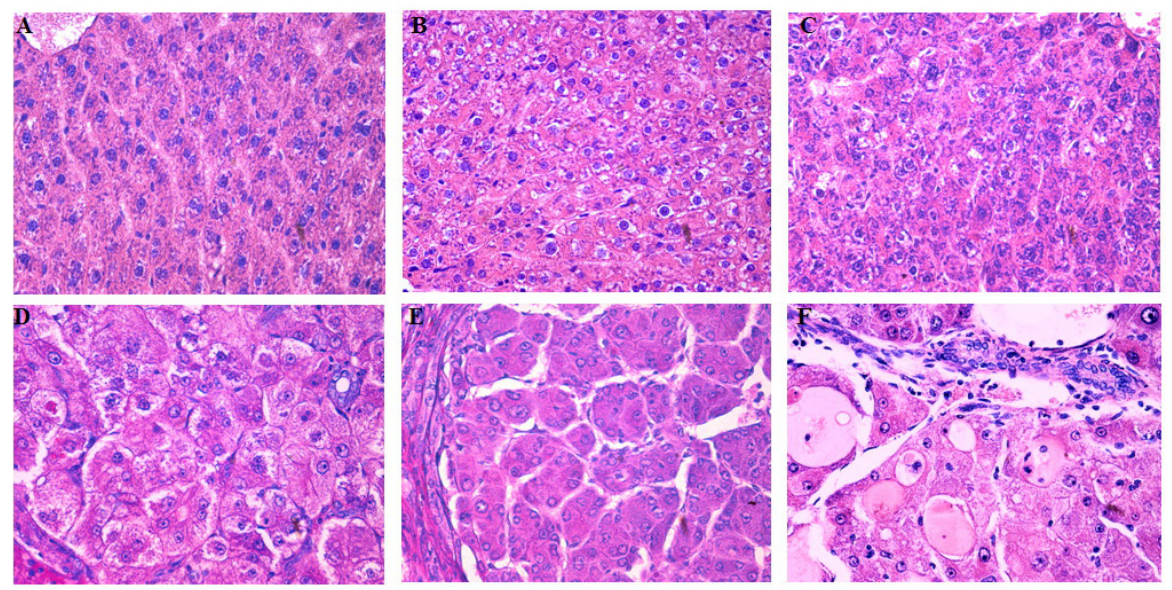

Figure 1. Histopathological changes of liver tissues obtained from model of rats following 0 (A), 5 (B), 8 (C), 12 (D) 16 (E), and 18 (F) weeks of DENA administration (HE, 40×).

\section{Validation of chip results by real-time RT-PCR}

The genes surveyed were composed of trim 24 down-regulated in liver carcinogenesis, mgmt and spink3 up-regulated at two time points of LC, myc, spp 1, and ggt1 up-regulated at three time points, ccndl up-regulated at four time points, and alpl and cyplal up-regulated during the entire process of liver carcinogenesis obtained from the chip data. On the other hand, they were involved in several different GO categories, including stimulus response, detoxification, oxidation reduction, immune/inflammatory response, amino acid and protein metabolism, cell proliferation, adhesion, DNA repair, and transcription regulation. Consequently, the nine genes above were selected for real time RT-PCR assays to evaluate the validity of the chip data in this study. The results indicated that, on the whole, expression profiles of these nine genes detected by real-time RT-PCR were in accordance with those obtained by chip analysis in the $5,8,12,16$, and 18 th weeks of rat liver cancer, although there were somewhat differences in the relative degree of up or down-regulation measured by the above two methods, suggesting array results were reliable (Figure 2).

\section{Global gene expression profiles of liver tissues in rat liver cancer occurrence}

Rat Genome 230 2.0 Array was used to detect gene expression profile of liver tissues on a genome-wide scale from male rats following 5, 8, 12, 16, and 18 weeks of DENA induction. It was found that 909 known genes, including 637 up-regulated, 270 down-regulated, and 2 up/down-regulated genes, were significantly changed in expression. Among them, 108 genes were significantly expressed at 5th, 213 at 8th, 516 at 12th, 698 at 16th, and 506 at 18 th 
week of LC. According to the GO database, 909 genes above were involved in 23 physiological activities. In detail, 48 genes associated with stimulus response, inflammation and immune response, oxidation reduction, nucleic acid metabolism, cell proliferation, and cell adhesion were up-regulated, while 39 genes associated with material transport, lipid metabolism, protein metabolism, cell differentiation, development and biogenesis were down-regulated at the 5th week of LC. A total of 96 genes associated with stimulus response, inflammation and immune response, gene transcription, material metabolism, cell proliferation, apoptosis, and adhesion were up-regulated, whereas 69 genes associated with enzyme linked receptor protein signaling pathway, material transport, lipid metabolism, and cell migration were down-regulated at the 8th week. A total of 310 genes associated with stimulus response, inflammation and immune response, enzyme linked receptor protein signaling pathway, gene transcription, material transport, metabolism of carbohydrate, lipid, nucleic acid, amino acid and protein, cell proliferation, apoptosis, growth, differentiation, development, biogenesis, regeneration, migration, adhesion, and angiogenesis were up-regulated, while 120 genes associated with detoxification, lipid metabolism, organic acid metabolism, and oxidation reduction were down-regulated at the 12th week. 353 genes associated with stimulus response, inflammation and immune response, enzyme linked receptor-, small GTPase-, G-protein coupled receptor-, Wnt-mediated signaling pathways, protein kinase cascade, substance metabolism, cell proliferation, apoptosis, regeneration, migration, adhesion, and angiogenesis were up-regulated, whereas 135 genes associated with detoxification, material transport, lipid metabolism, organic acid metabolism, and oxidation reduction were down-regulated at the 16th week. A total of 293 genes associated with stimulus response, inflammation and immune response, enzyme linked receptor-, small GTPase-, Wnt-mediated signaling pathways, gene transcription, substance metabolism, cell proliferation, apoptosis, regeneration, migration, adhesion, and angiogenesis were up-regulated, while 122 genes associated with detoxification, material transport, metabolism of carbohydrate, lipid and organic acid, oxidation reduction, cell differentiation, and development were down-regulated at the 18th week (Table 2).

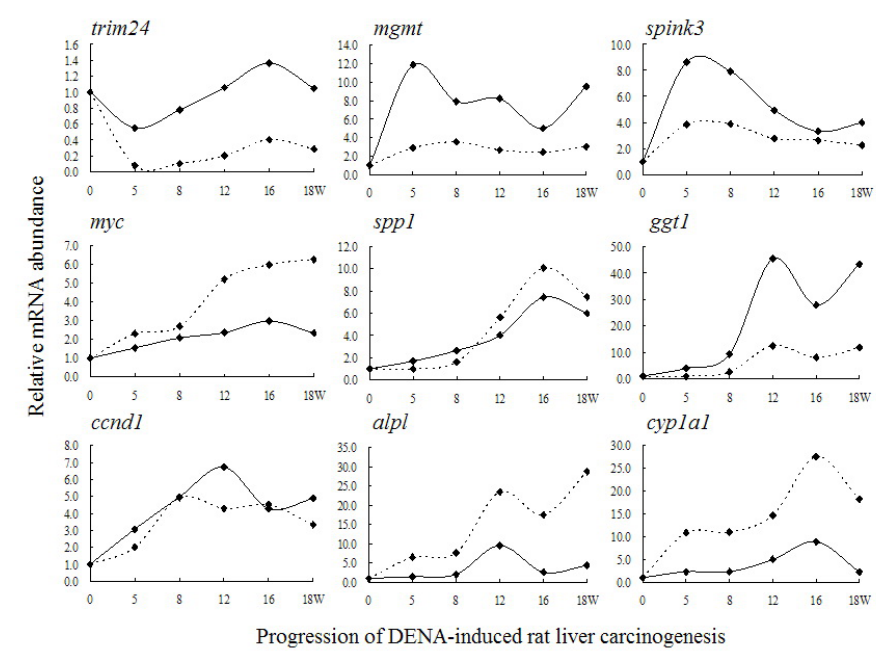

Figure 2. Verification of gene expression in DENA-induced rat liver cancer by real-time RT-PCR. The results of RT-PCR and Rat Genome 230 2.0 Array are presented as a real line and a dotted line, respectively. 


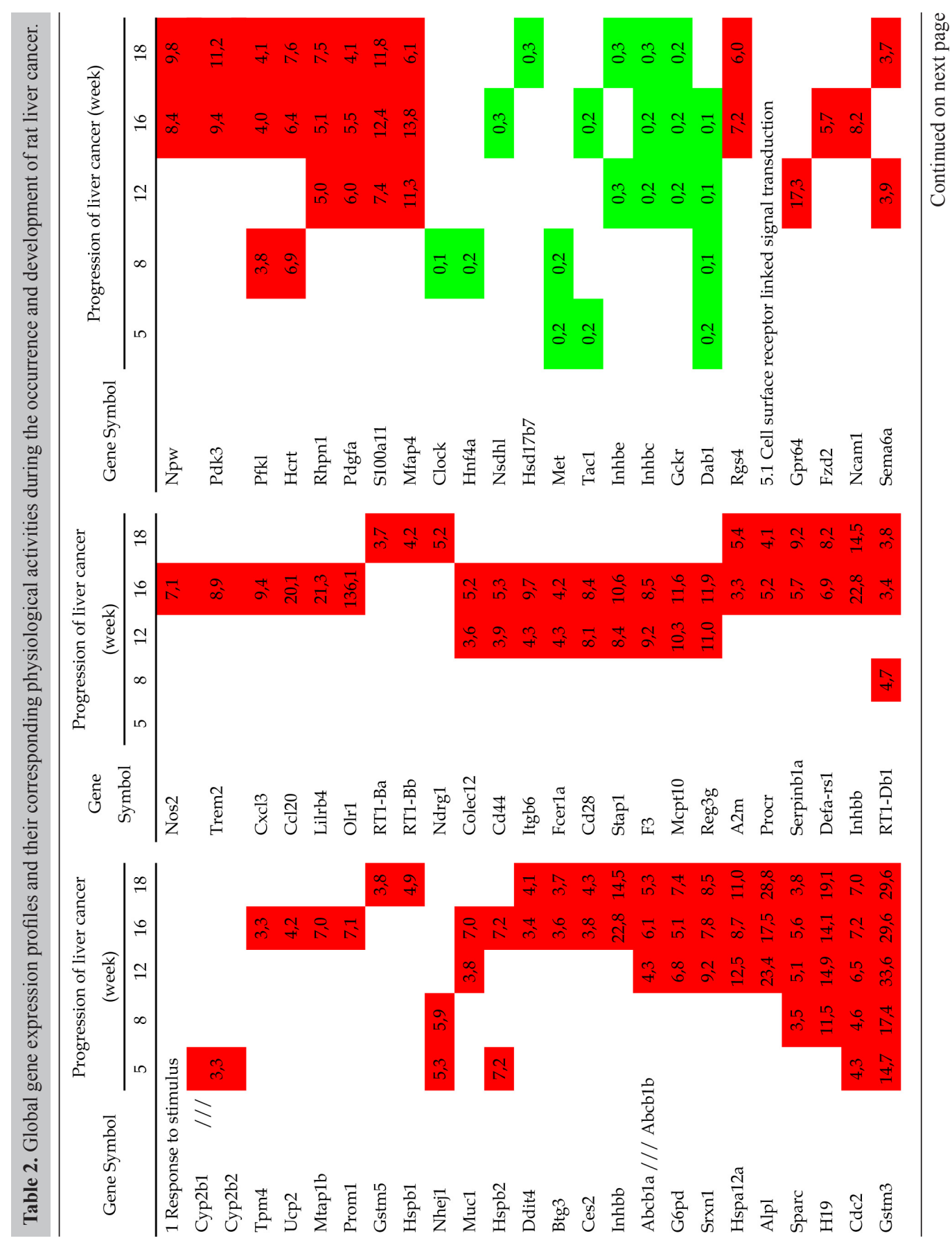




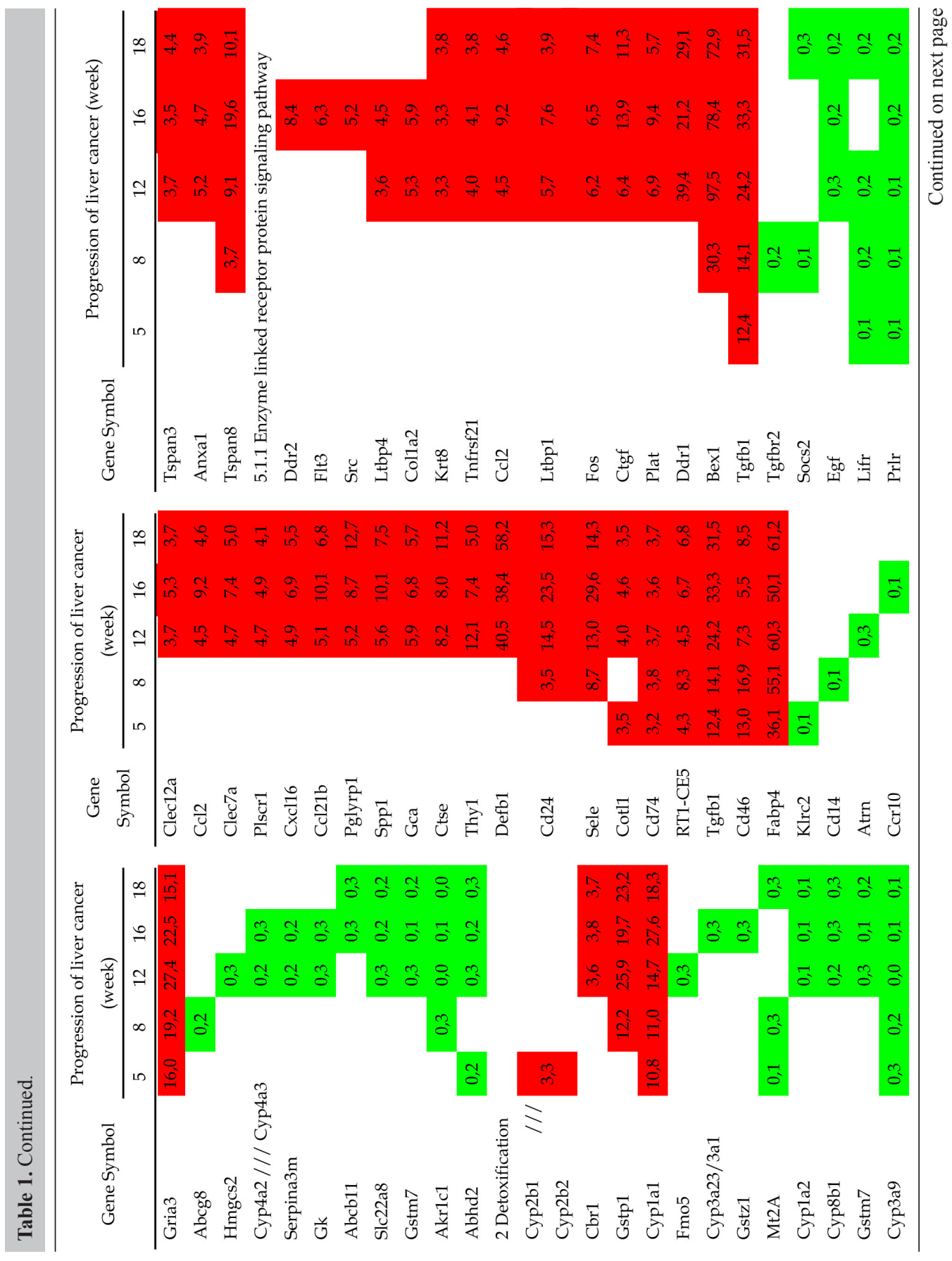




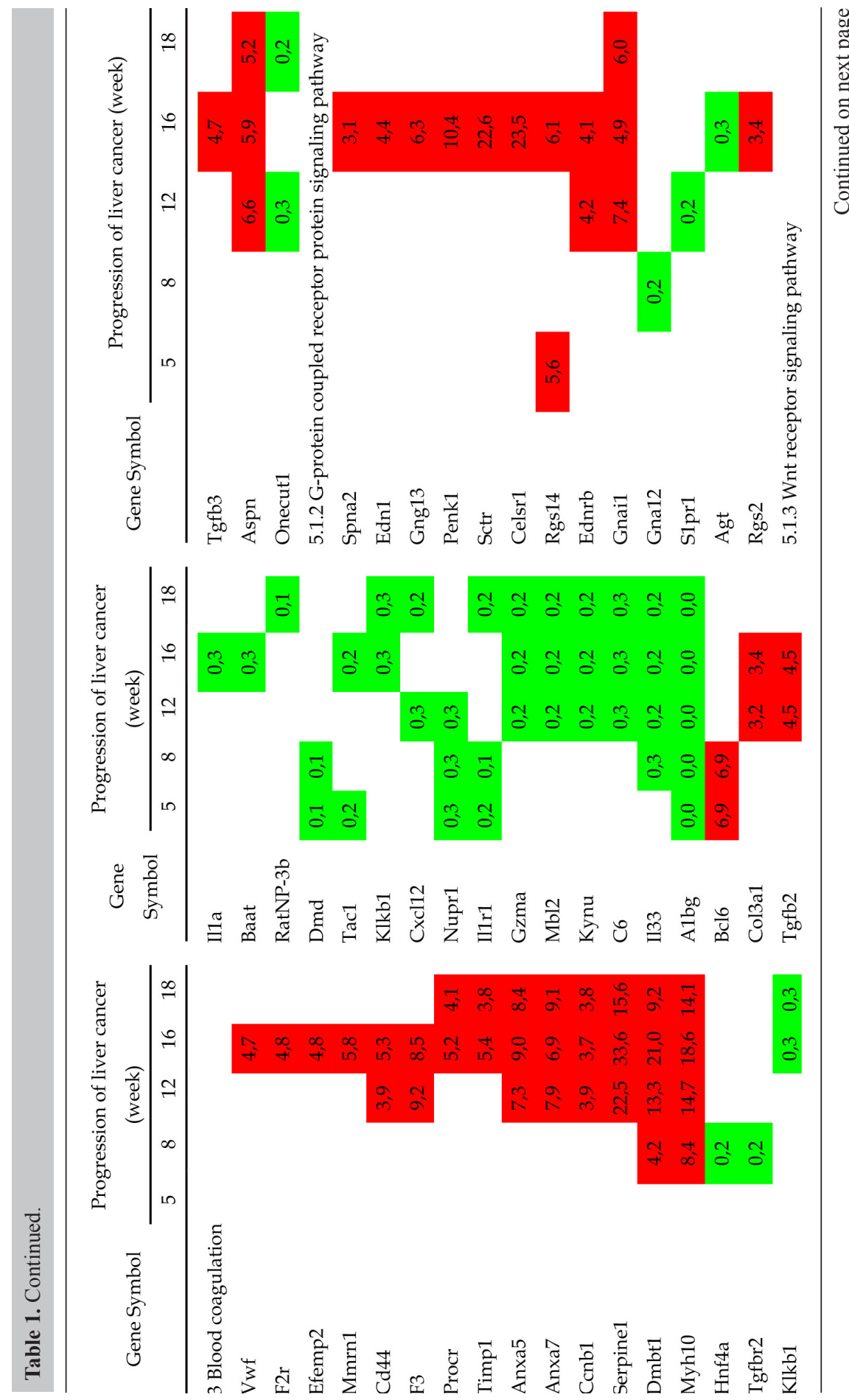




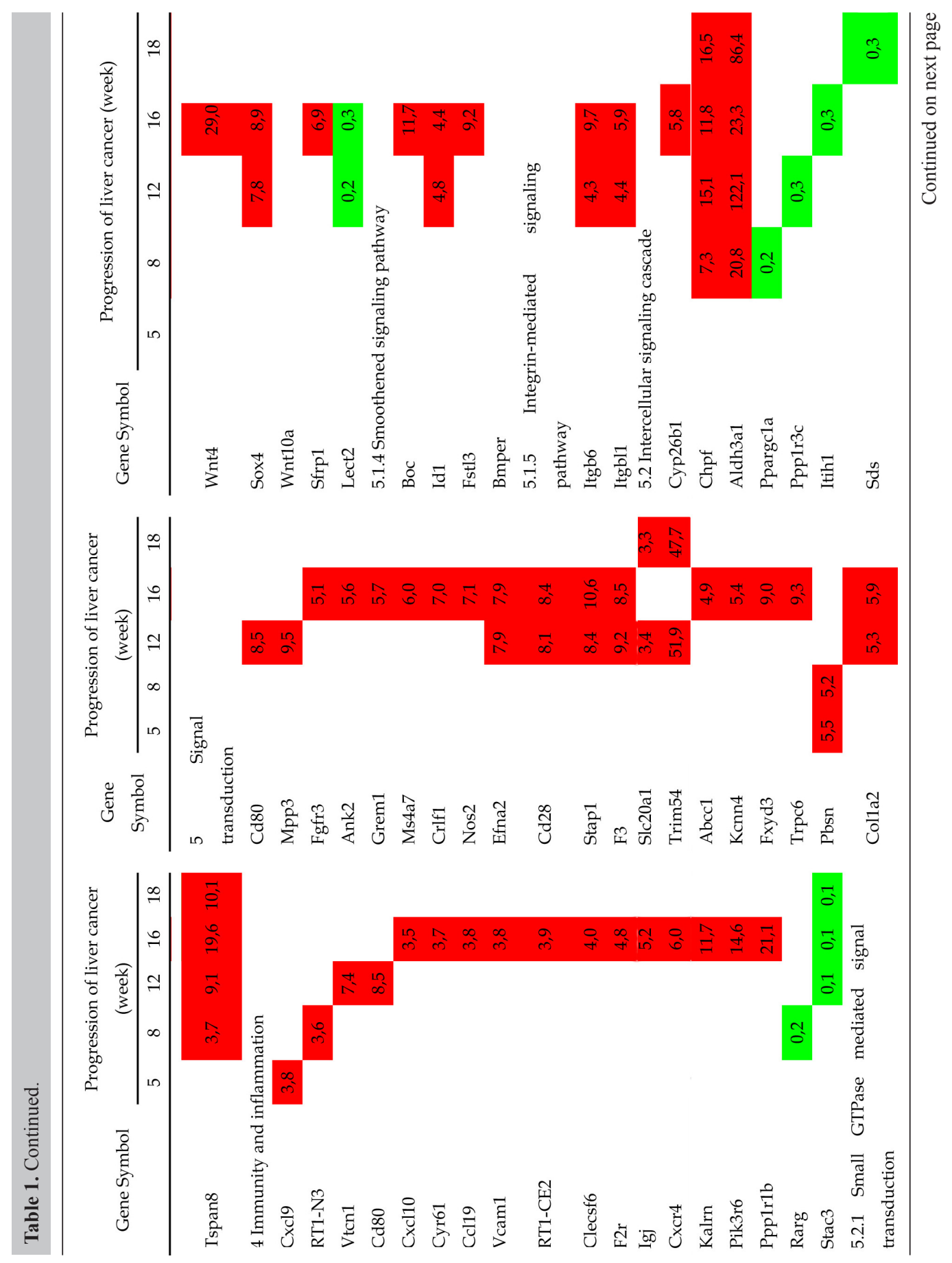


Hepatic gene expression profile of rat liver cancer

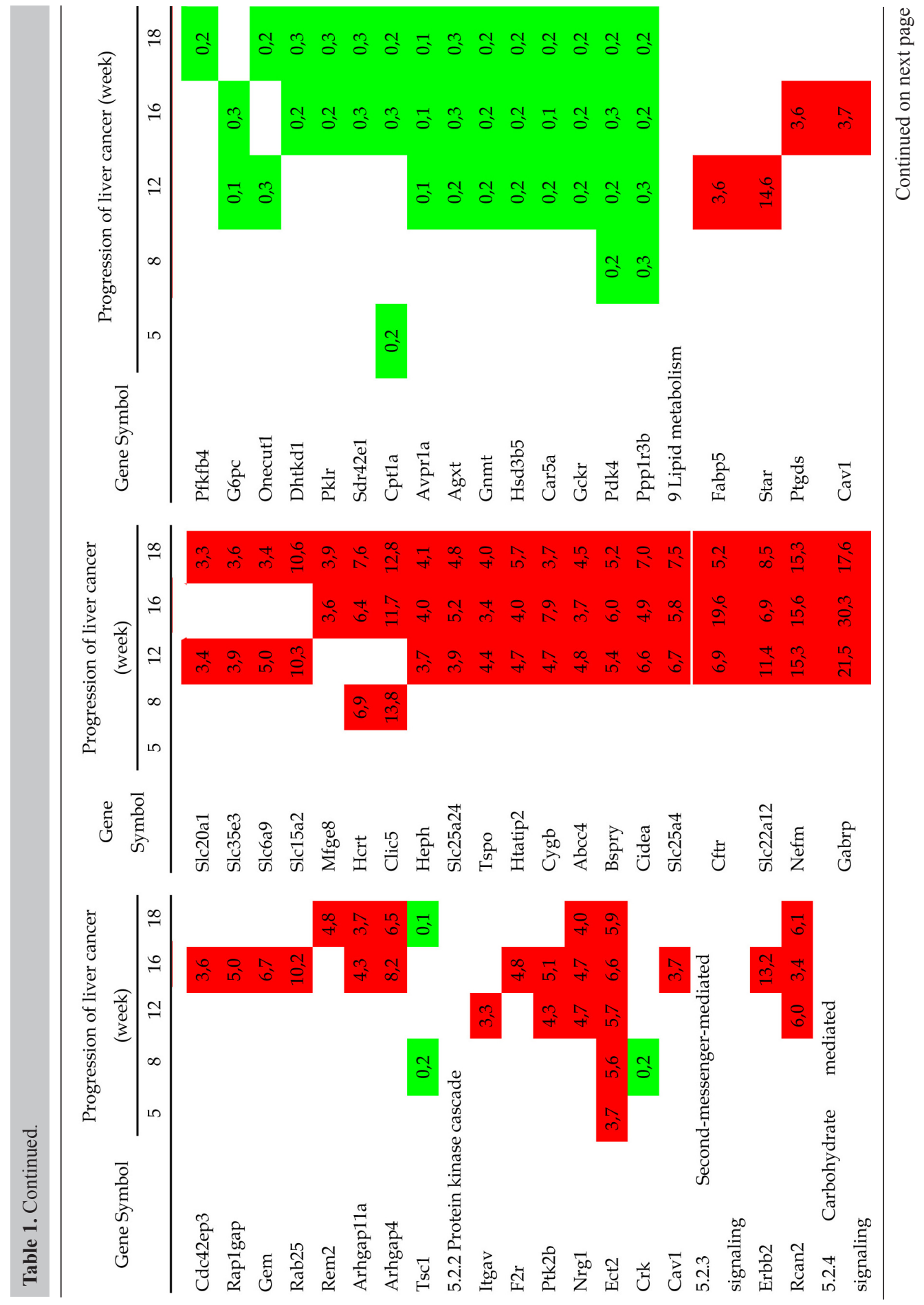




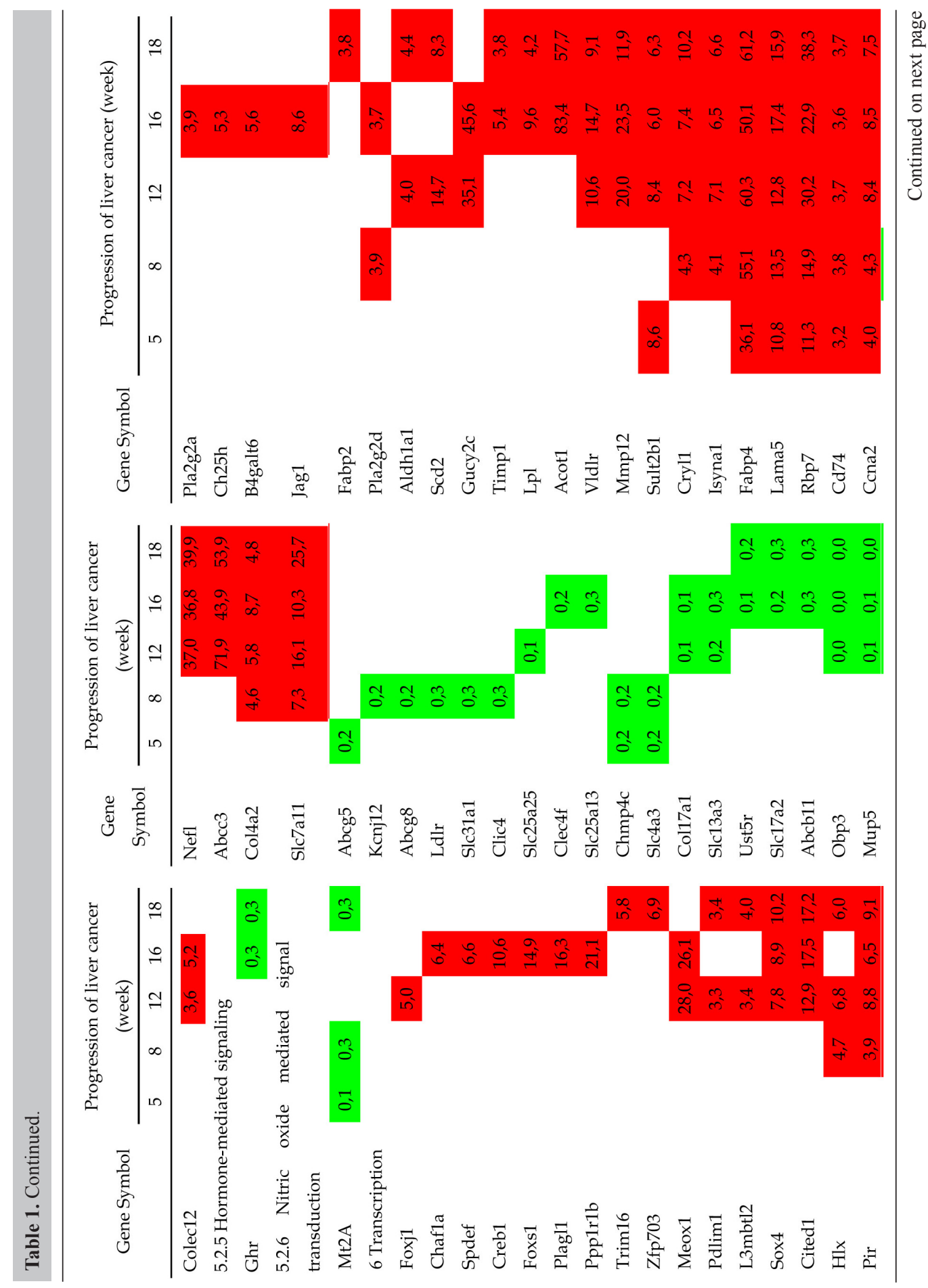


Hepatic gene expression profile of rat liver cancer

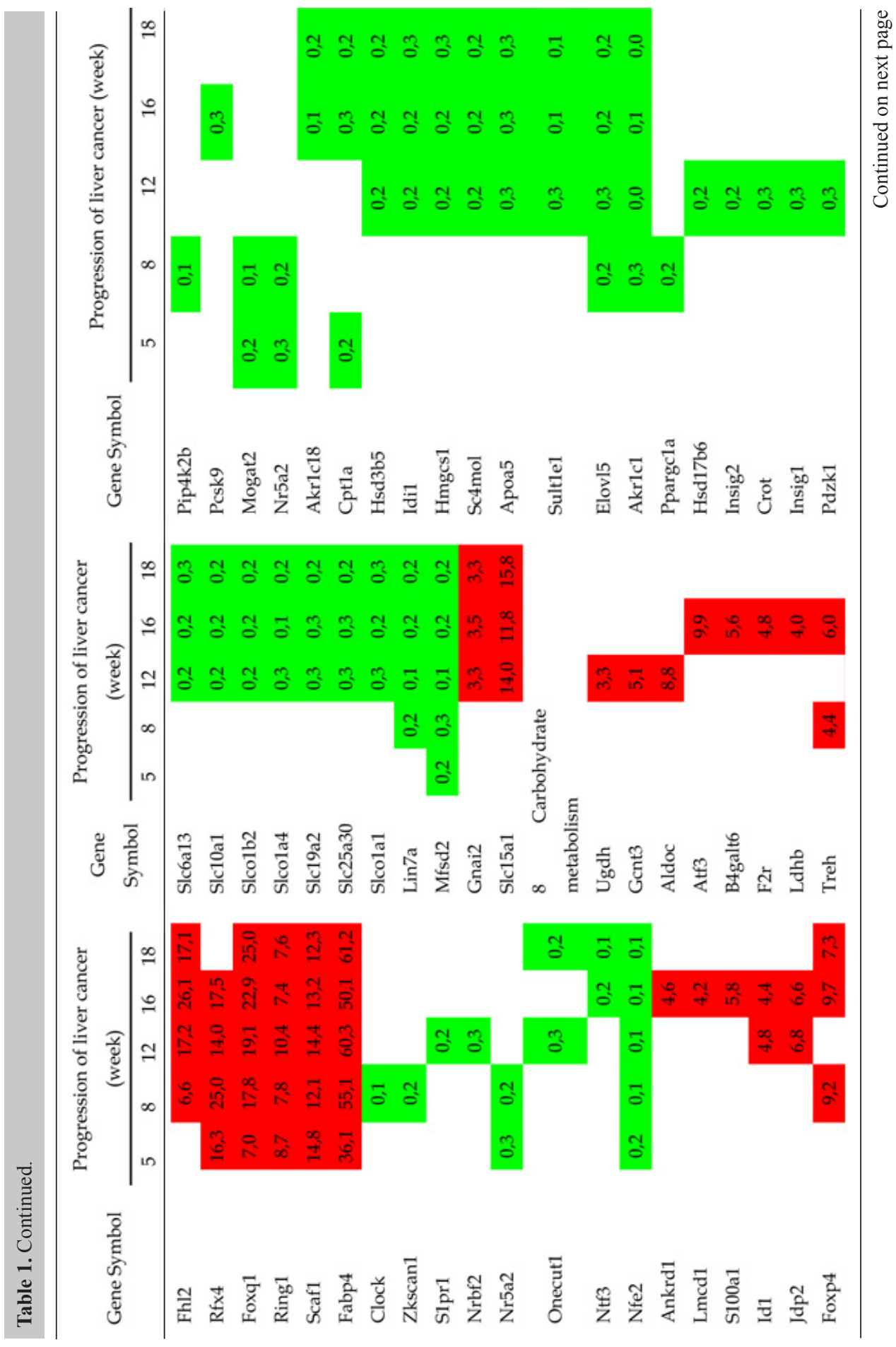


C.S. Xu et al.

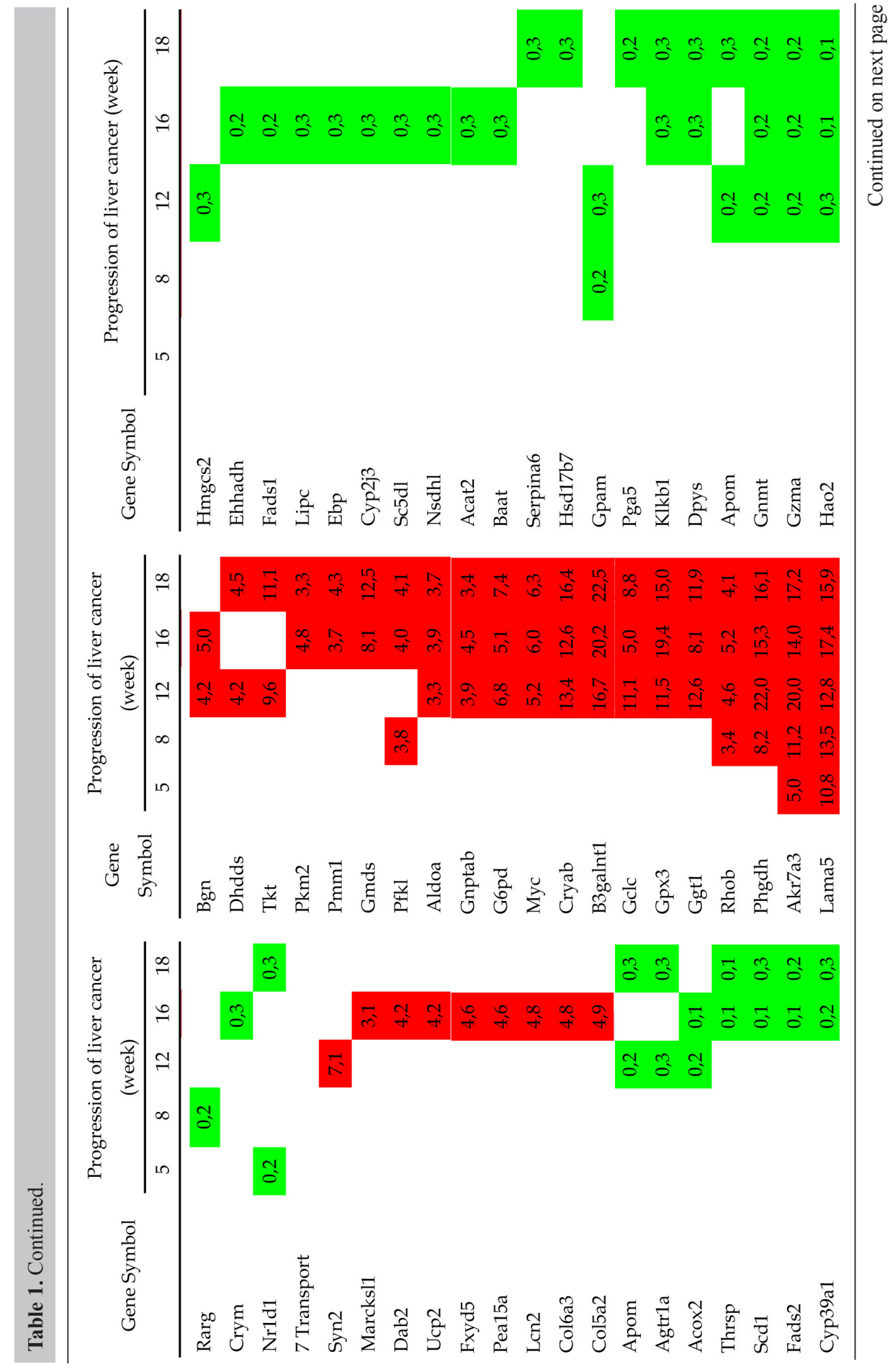


Hepatic gene expression profile of rat liver cancer

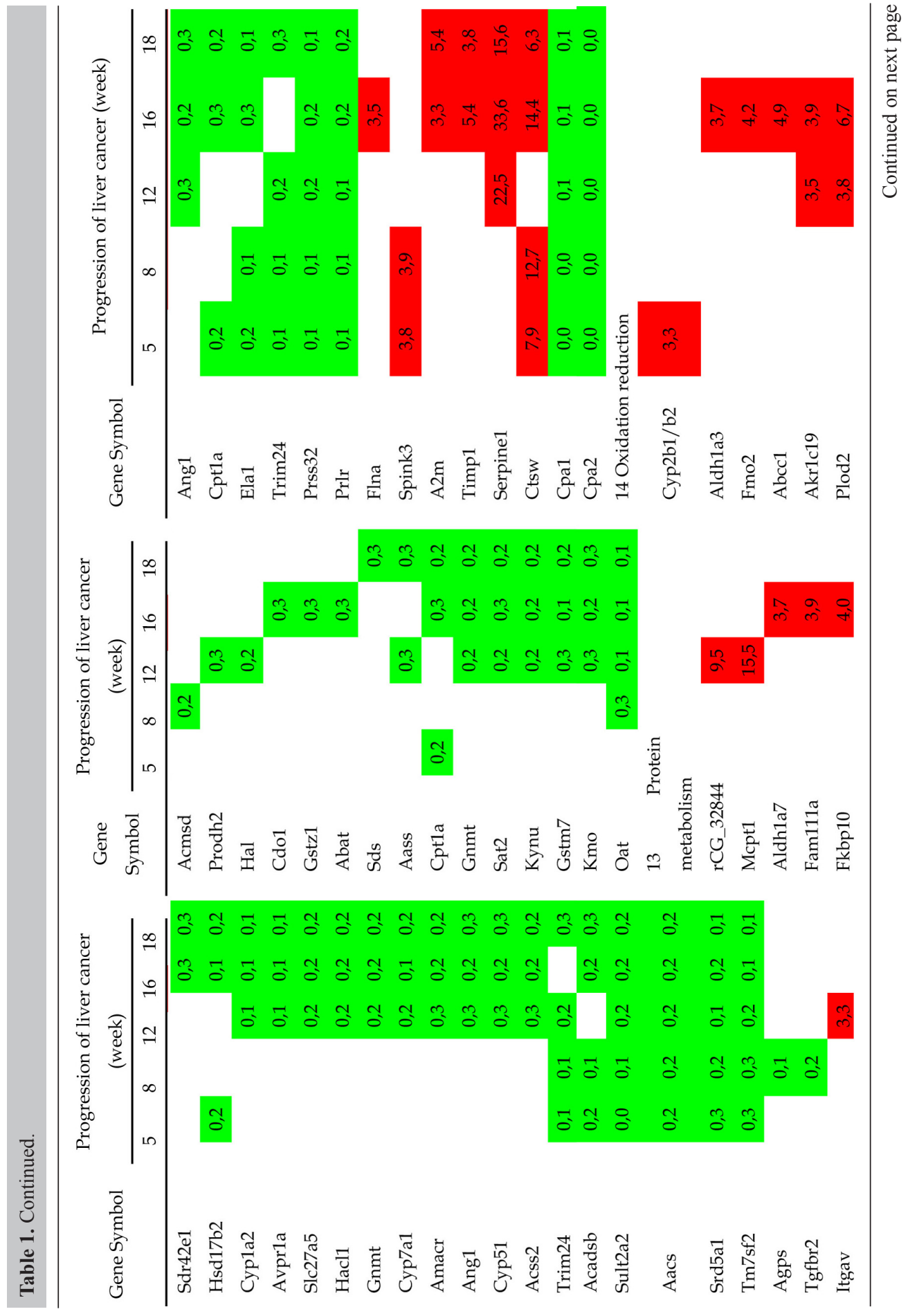


C.S. Xu et al.

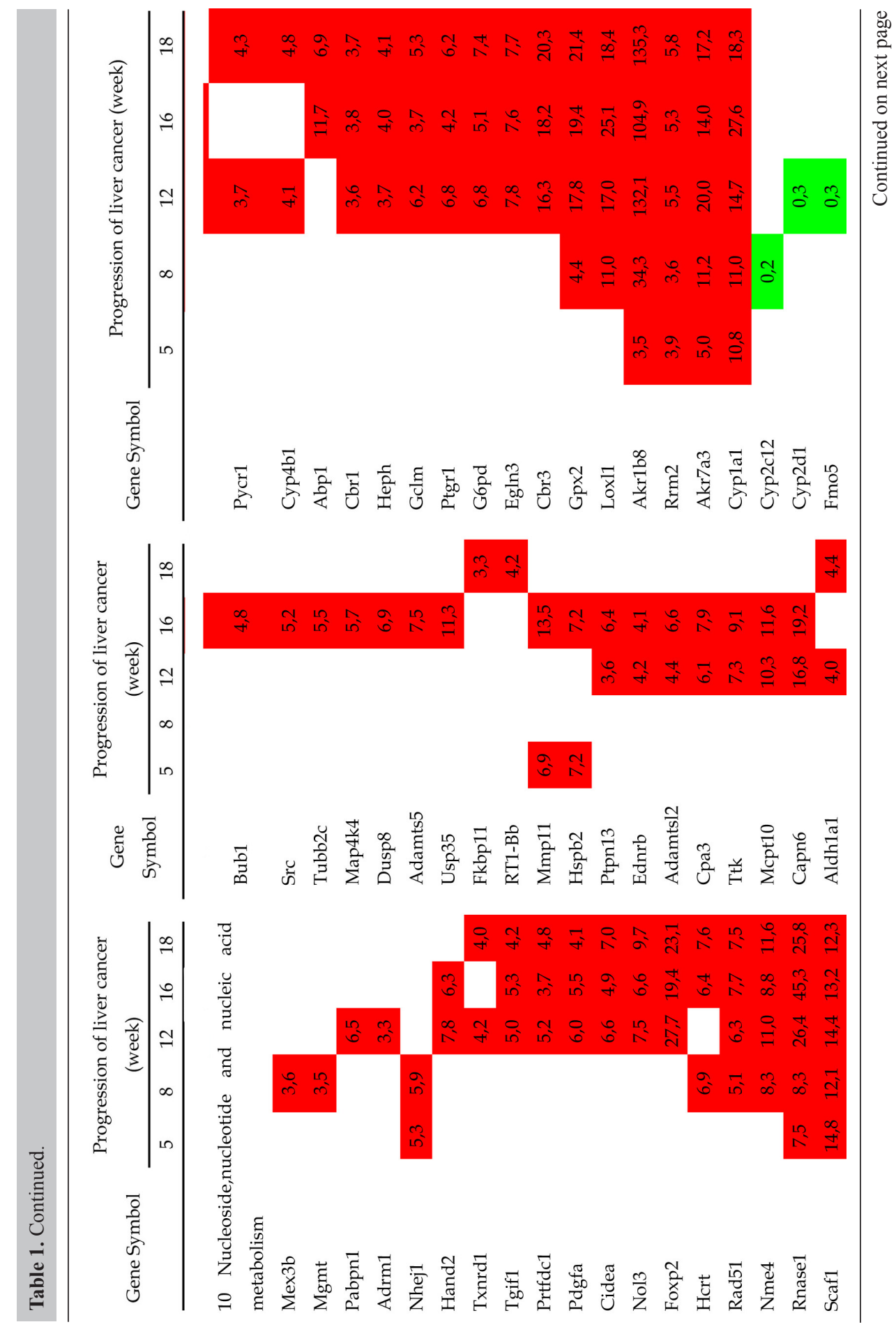




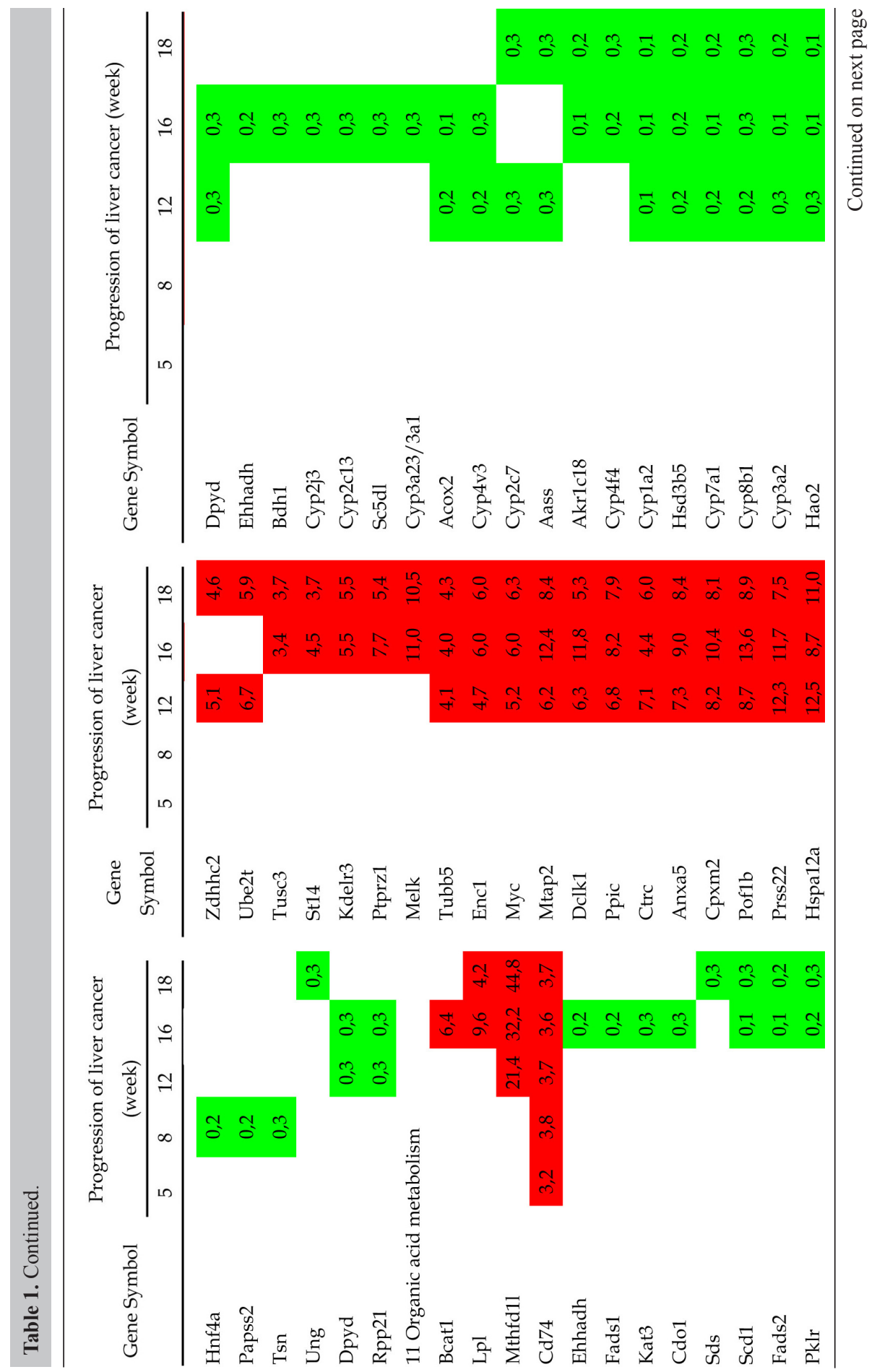


C.S. Xu et al.

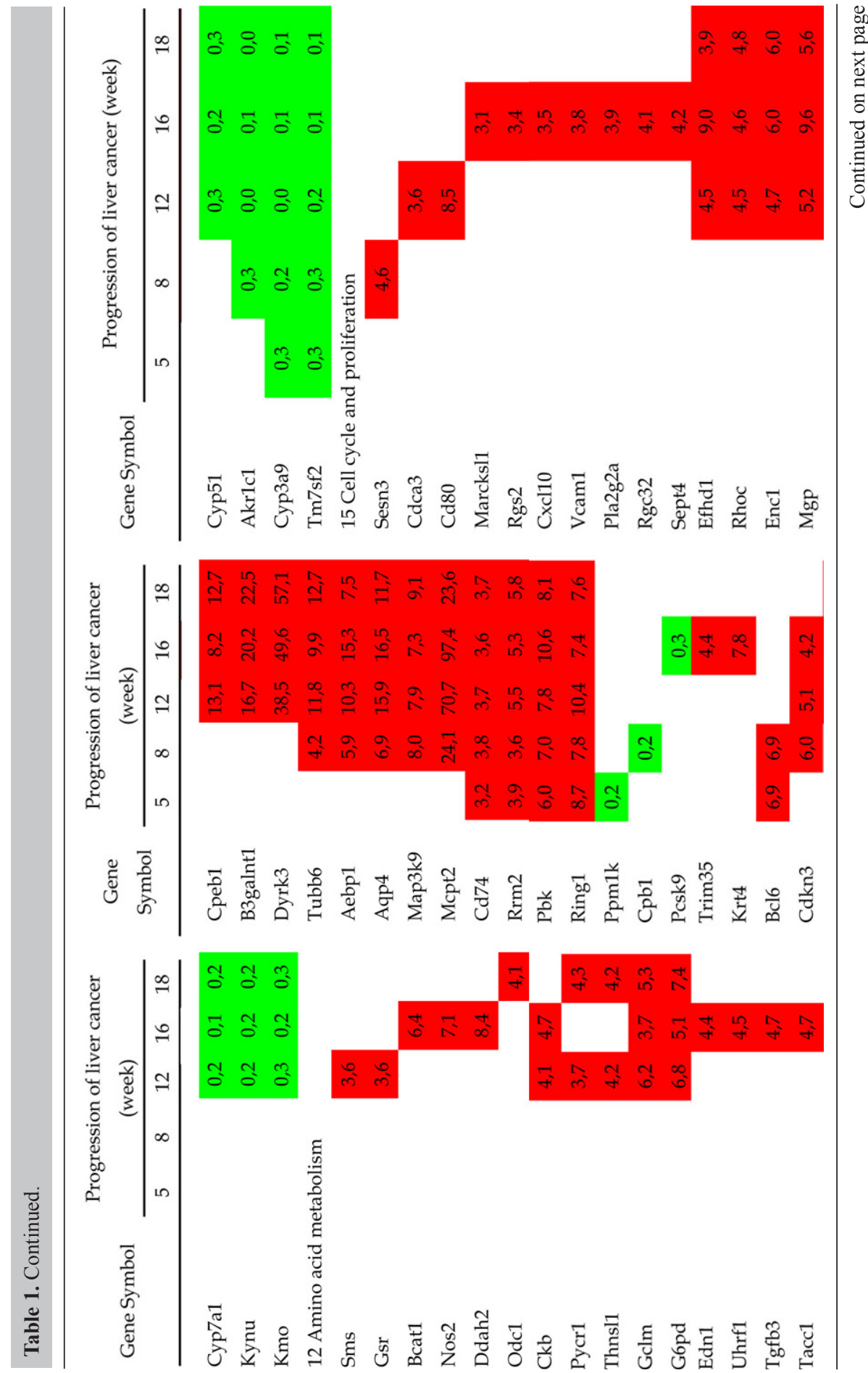


Hepatic gene expression profile of rat liver cancer

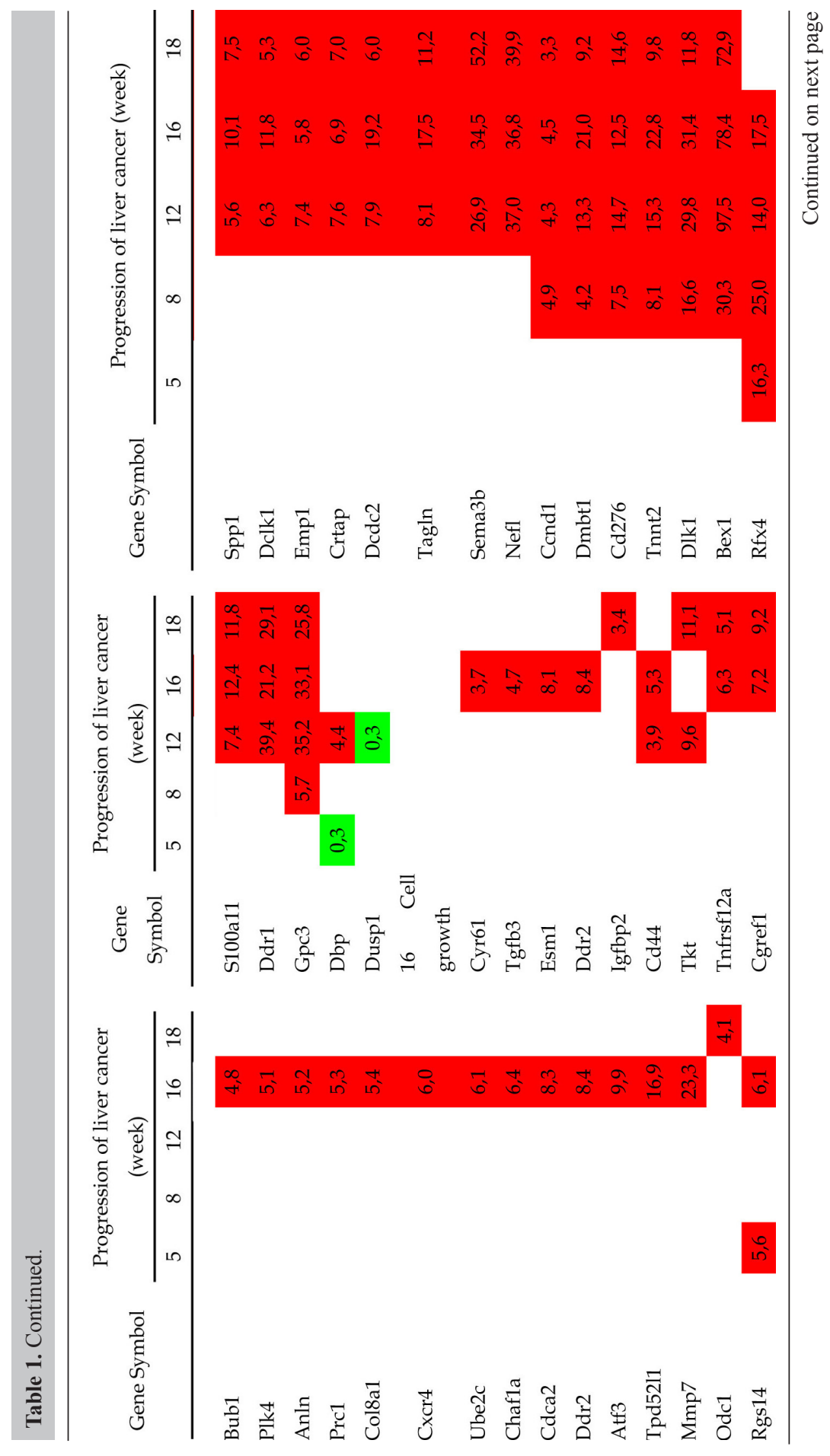




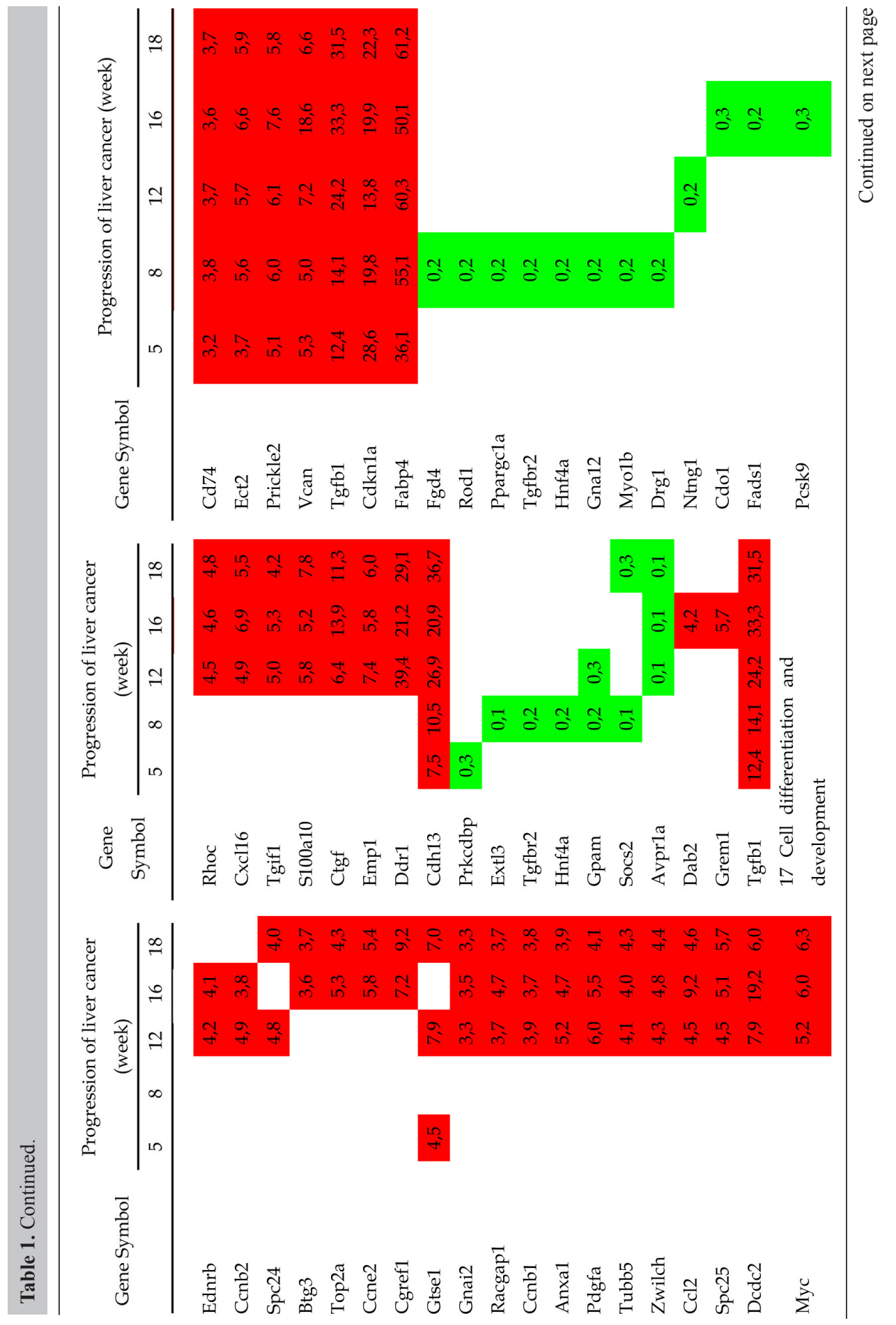


Hepatic gene expression profile of rat liver cancer

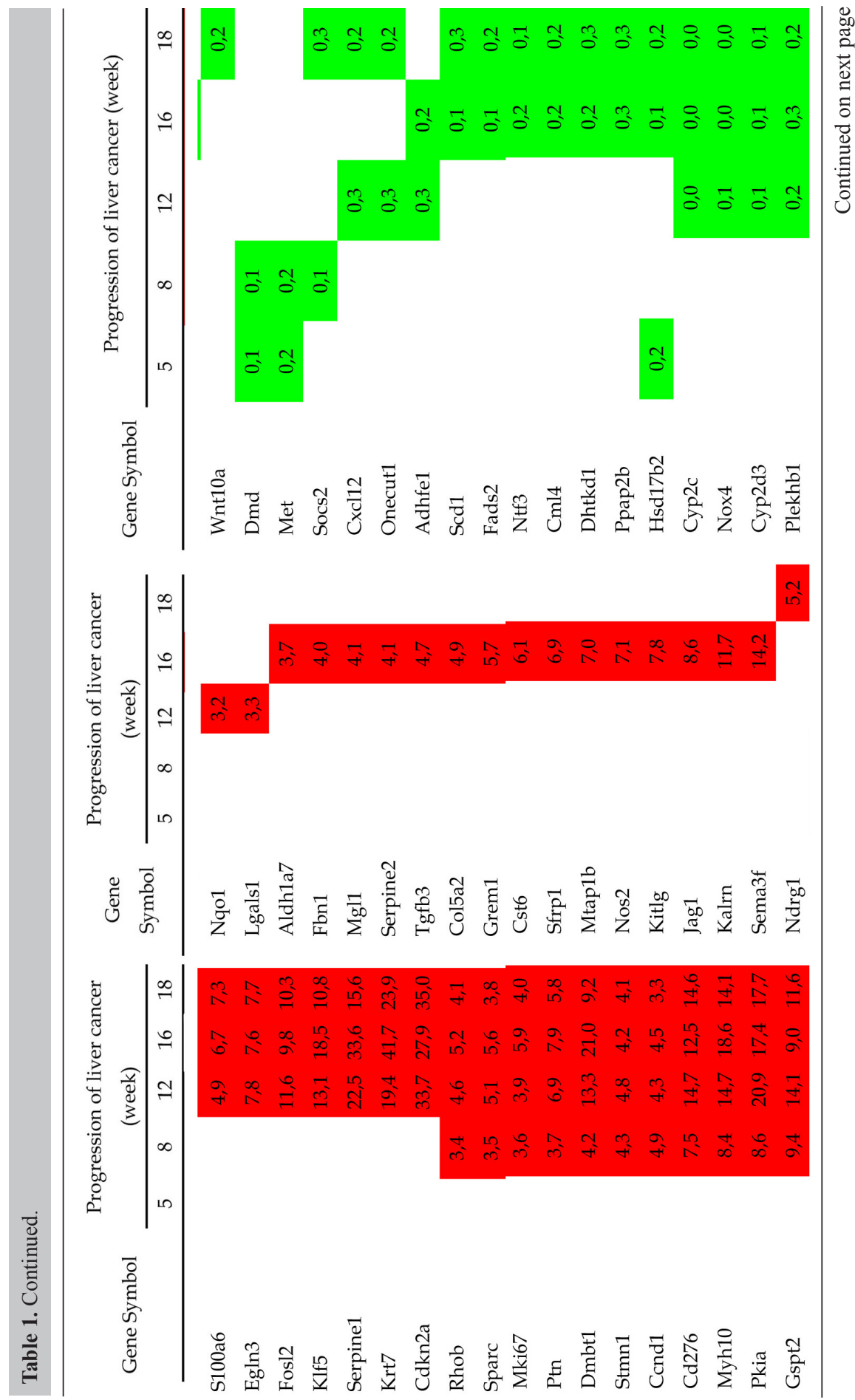




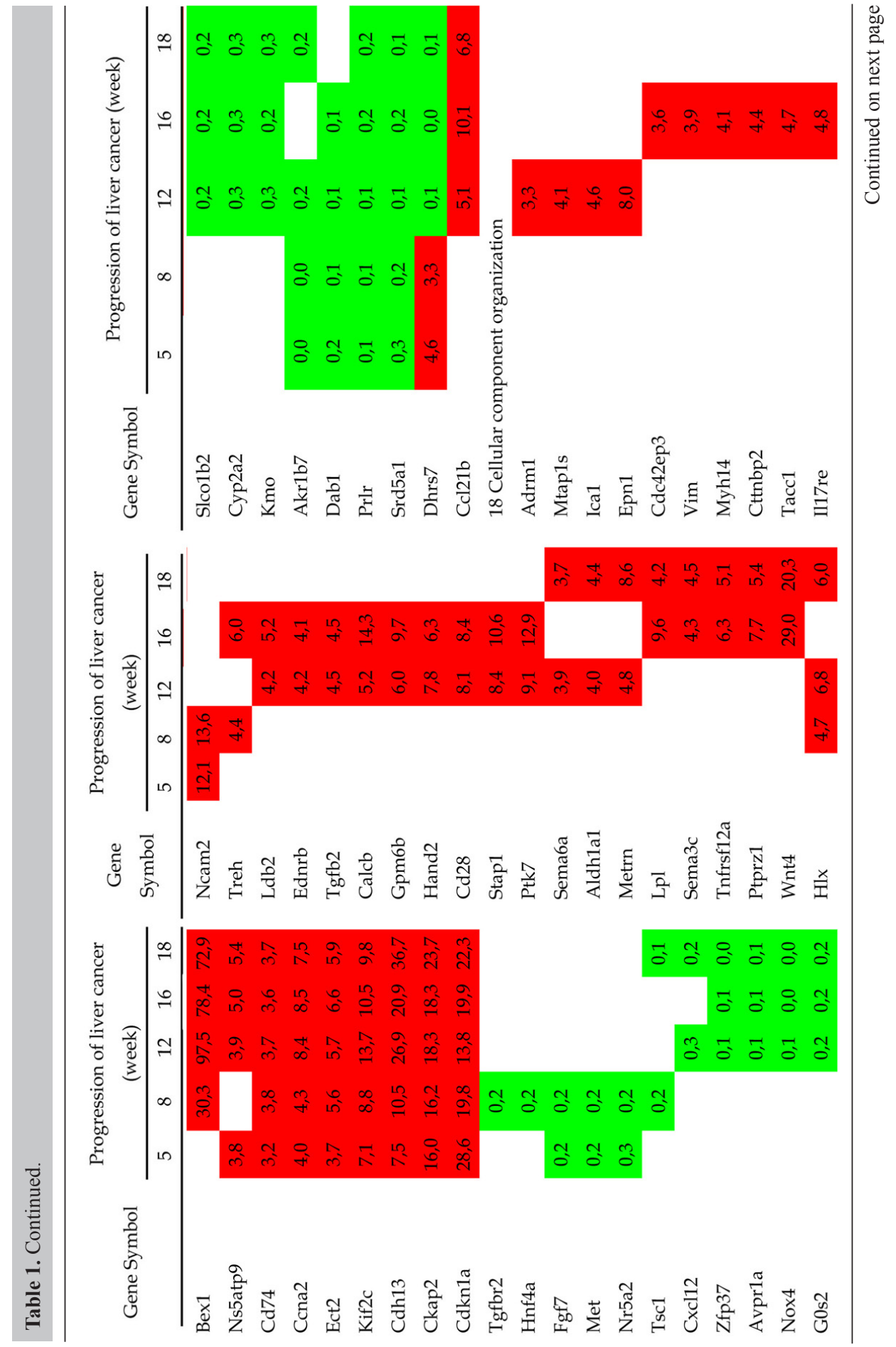




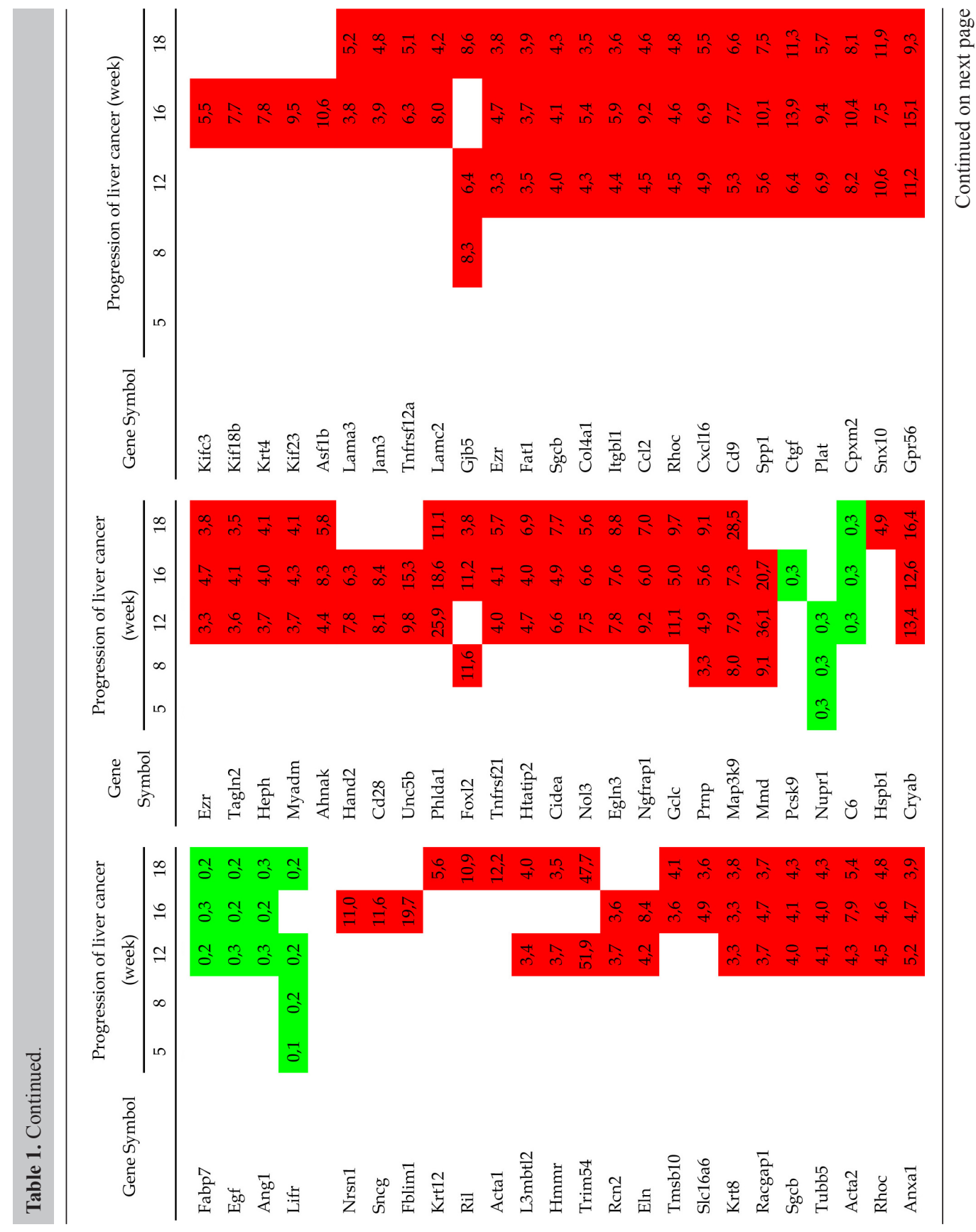




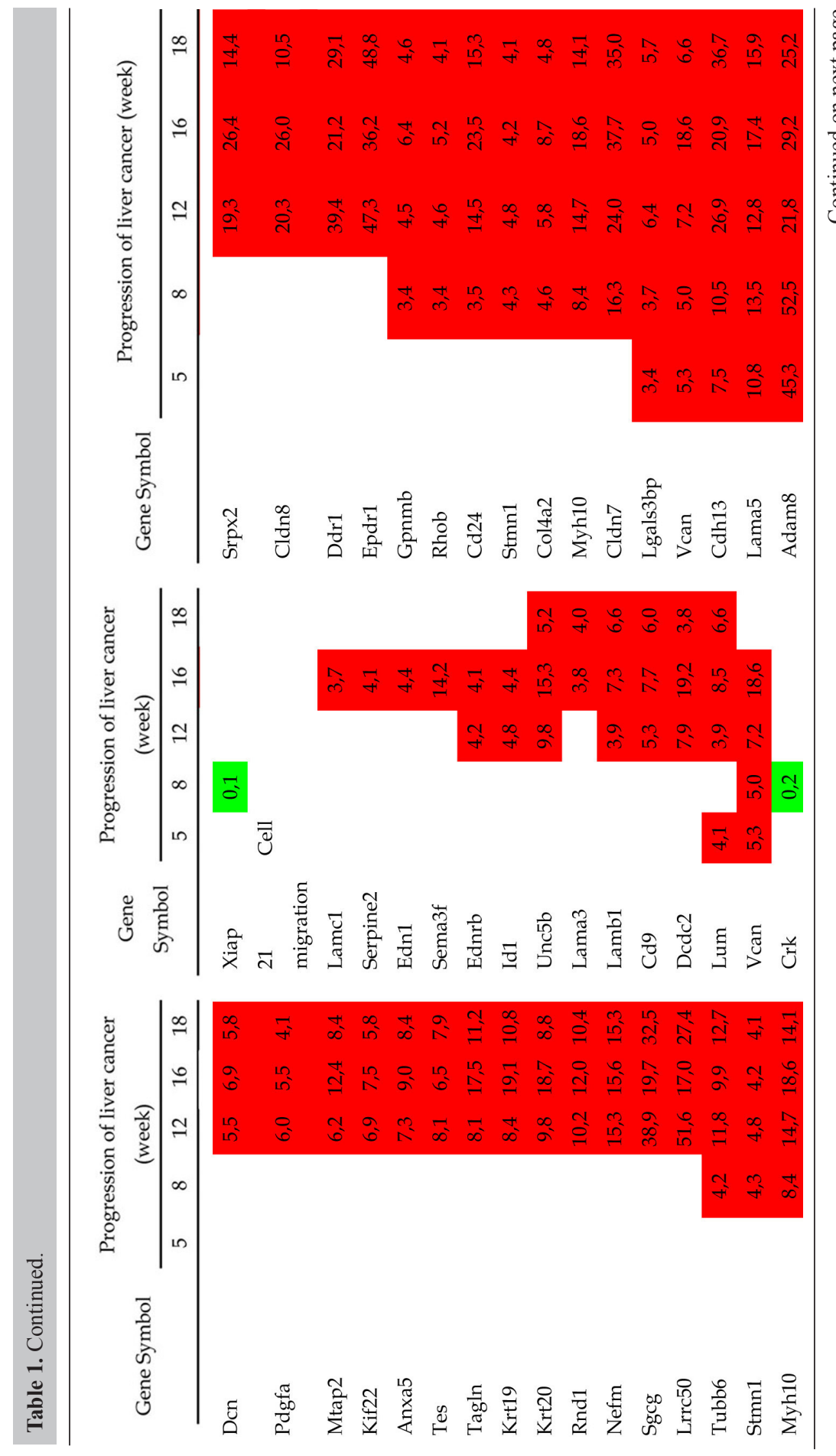




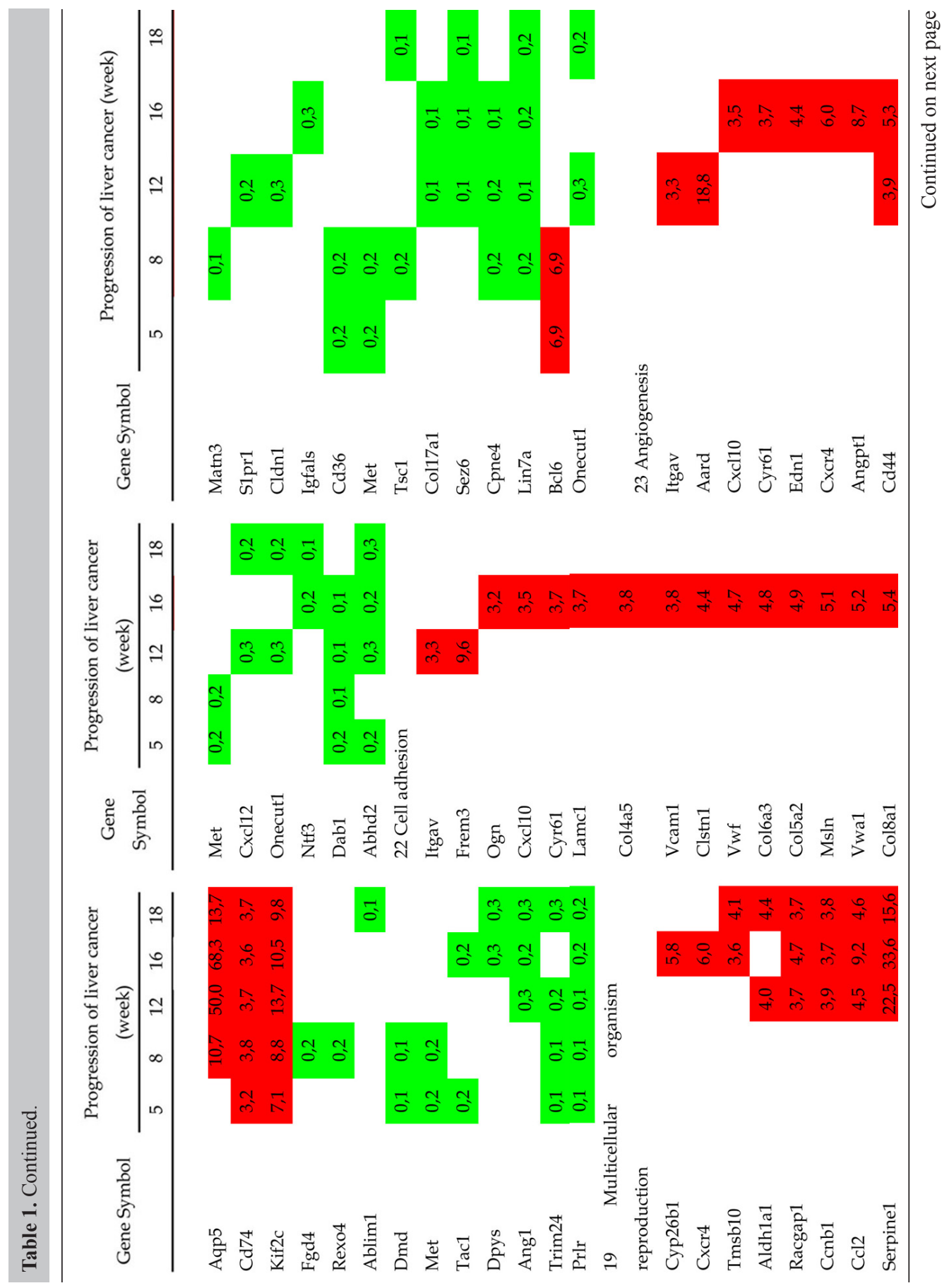


C.S. Xu et al.

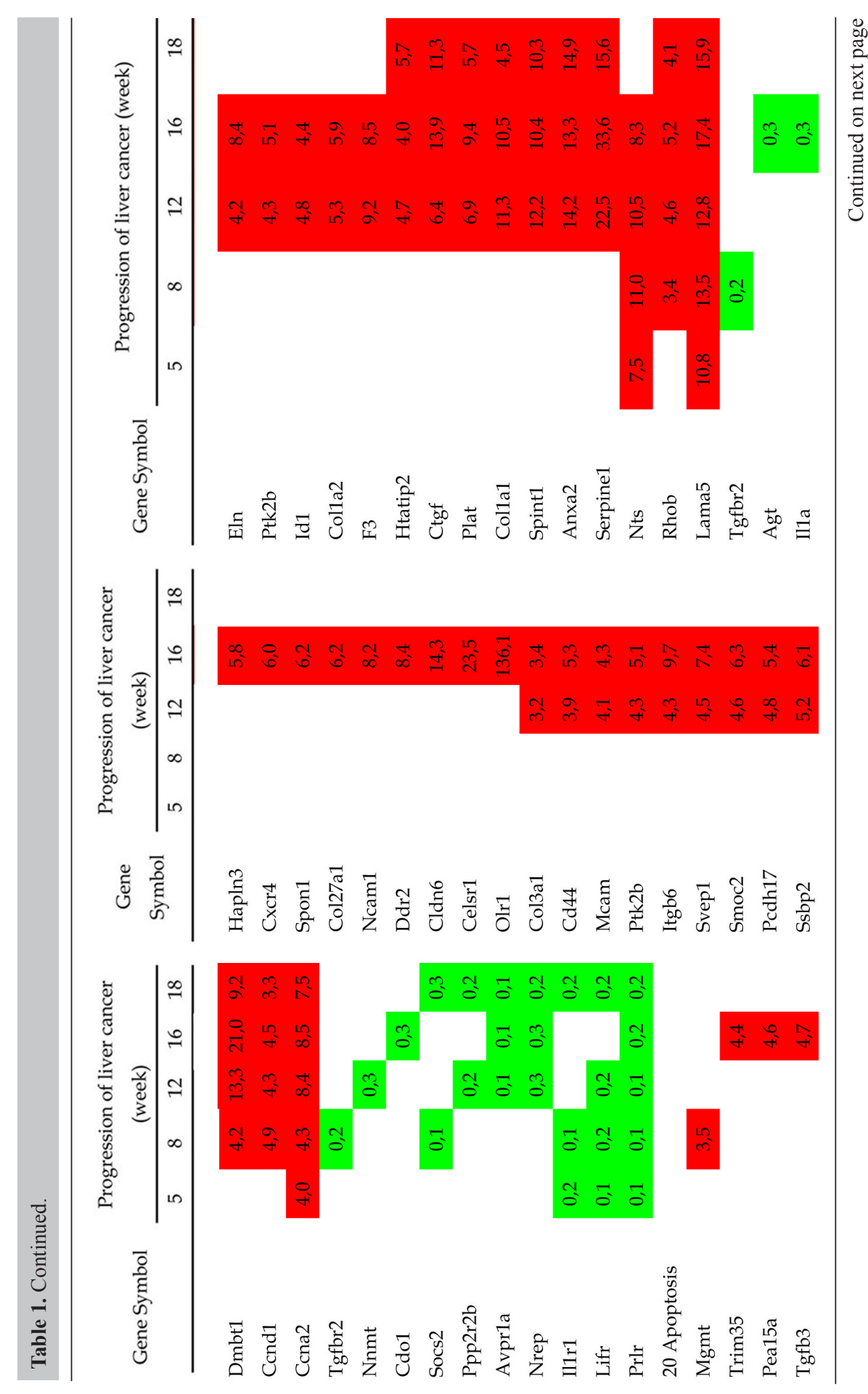


Hepatic gene expression profile of rat liver cancer

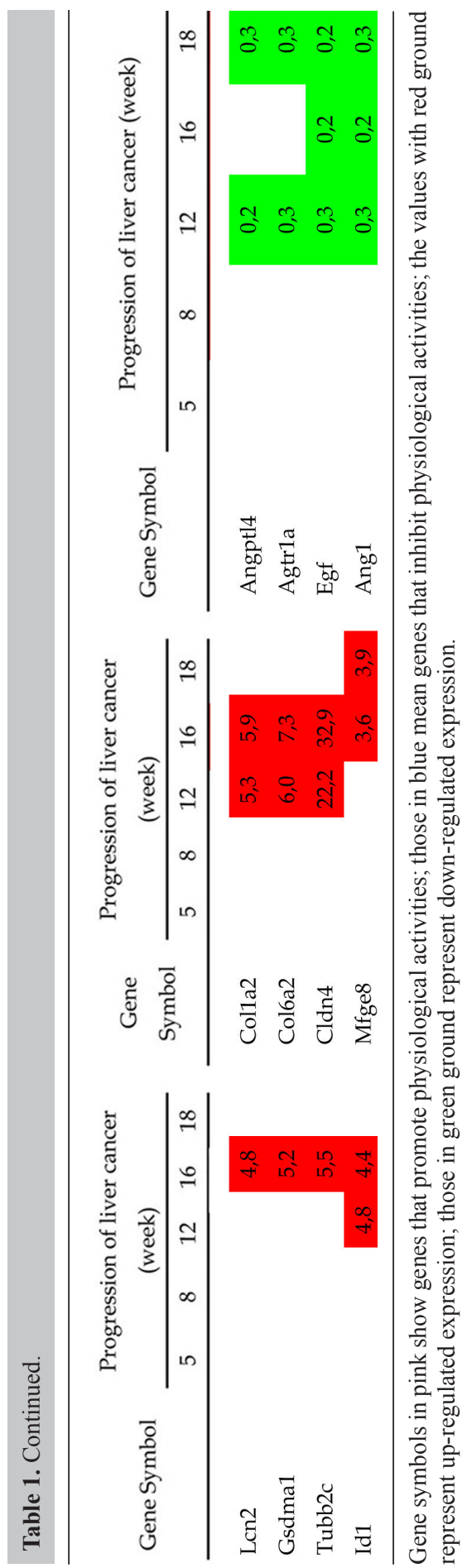




\section{Changes in physiological activities uncovered by gene expression profiles of liver tissues during rat $\mathrm{LC}$}

The mathematical model $\left(E_{t}\right)$ was used to analyze all of the physiological activities uncovered by gene expression changes of liver tissues during rat liver carcinogenesis. It was demonstrated that, in the 5th week, inflammation response, oxidation reduction, and cell proliferation in DENA-induced group were significantly increased than those in NC group, while lipid and organic acid metabolism were decreased. In the 8th week, the hepatic response to stimulus and inflammation increased, lipid and organic acid metabolism remaining weak, while carbohydrate metabolism began to decrease. In the 12th week of rat LC, stimulus response and cell proliferation remained augmented, and angiogenesis began to increase. In the 16th week of rat LC, the activities of stimulus response, oxidation reduction, cell proliferation, differentiation, migration, adhesion, and angiogenesis were enhanced. In the 18th week of rat LC, hepatic response to stimulus and inflammation, amino acid metabolism, cell proliferation, and cell differentiation were augmented. Moreover, weak carbohydrate, lipid and organic acid metabolism in DENA-induced group were persistently observed at 12-18w (Figure 3).

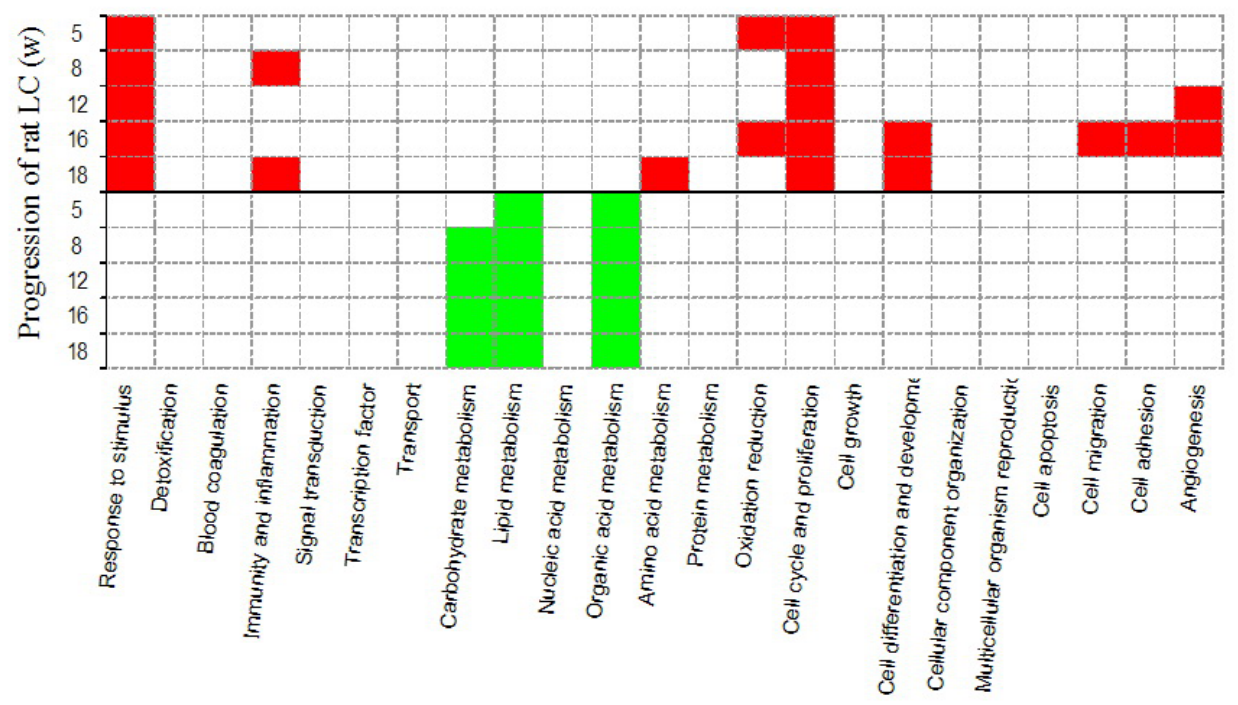

Figure 3. Twenty-three kinds of physiological activities of liver tissues during rat liver cancer occurrence. Physiological activities stronger than control; — Physiological activities weaker than control.

\section{DISCUSSION}

Previous studies have proved that angiogenesis, inflammation response, materials metabolism, cell proliferation, growth, apoptosis, migration and adhesion, etc., were closely related to the occurrence and development of LC. Among them, stimulus response and oxidation reduction, involved in conversion of carcinogenic agents to active form, reduction of toxicity and elimination of drug/toxin deviations, were closely related to the occurrence and development of liver tumor (Valles et al., 2003; Xue, 2005). The present study showed that 
three members of cytochrome P450s (CYPs) family, including cyp 1a1, cyp4b1, and cyp11a1, were up-regulated in LC, and maybe participate in carcinogenesis by converting DENA to an active electron-withdrawing group (Rodriguez-Antona and Ingelman-Sundberg, 2006). The significant increases in cyp $1 b 1$ and cyp $2 c 40$ expression were observed in breast or liver carcinomas, providing some therapy targets and potential prognosis factors (McFadyen and Murray, 2005; Vaclavikova et al., 2007), but their augmented expressions were not found in our study. Clearly, further investigation is needed to determine the role(s) of CYPs in hepatocarcinogenesis. gclc, gclm, ggt1, gpx3, and sult $2 b 1$ involved in sulfur metabolism were up-regulated at $12-18 \mathrm{w}$ in liver cancer, suggesting that they might carry out detoxification of chemical carcinogen. Glutathione S-transferases Gstp1 and Gstm3 were enhanced in expression at all stages of liver tumor genesis with a 33 -fold increase at $12-18 \mathrm{w}$, indicating that reactive oxygen species and anti-oxidation defense existed and they might play important roles in the progression of liver tumor (Scibior et al., 2008). The expression change of gstm 3 in our research strikingly differed from the down-regulation of gstm 3 discovered by Liu et al. (2009) in liver cancer, which deserves further study. srxn1, tpm4, btg3, and ucp2 associated with oxidative stress were up-regulated at $12-18 \mathrm{w}$, and the members of aldehyde dehydrogenase, such as Aldh1a1, Aldh1a3 and Aldh3a1, were greatly increased in mRNA level. Above results indicated they may be involved in repressing the level of reactive oxygen species during hepatocarcinogenesis. In addition, $h s p b 1, h s p b 2$, and $h s p a 12 a$ related to stress response were up-regulated at one or more than one time points during liver cancer occurrence. The analysis of synergy value indicated that the $E_{t}$ of stimulus response-related genes was significantly higher than $E_{c}$ of the control during the entire period of hepatocarcinogenesis, and oxidative reduction-related genes at $5 \mathrm{w}$ and $16 \mathrm{w}$, suggesting stimulus response and oxidative reduction were strengthened, and may play an important role during the occurrence of liver cancer.

Epidemiology studies showed that chemotactic factors, cytokines, and reactive oxygen produced by inflammatory cells could mediate malignant transformation of the normal cells and angiogenesis, and then increase the risk of liver cancer occurrence (Jackson et al., 1997; Coussens and Werb, 2002). After liver damage was caused by DENA, the hepatic defense reaction, inflammation and immunity response to external stimuli deserved further investigation. The transcriptome atlas of liver tissues during LC occurrence showed that chemokine recruitment-promoting gene $\operatorname{cxcl} 9$ was up-regulated at the 5th week, antigen presentationpromoting gene $r t 1-n 3$ at the 8 th week, $c d 80$ associated with T cell activation at the 12th week, chemokines ccl19, ccl20, cxcl10, cxcl3, cxcr4, cyr61, and antigen presentation gene rt1-ce2 at the 16th week, antigen presentation molecules $r t 1-b a$ and $r t 1-b b$ at the 18th week. On the other hand, chemokines $\mathrm{Ccl} 2, \mathrm{Ccl} 21 \mathrm{~b}$, and Cxcl16 involved in promoting the activation of inflammatory cells were augmented in mRNA level at 12-18w, and cell surface molecules $c d 24, c d 46$, and $c d 74$ related to immune cells or inflammatory cell migration, adhesion, and interaction, were up-regulated during the entire occurrence and development of liver cancer. The synergy value $\left(E_{t}\right)$ of above inflammation and immune response-related genes was significantly higher than $E_{c}$ at the 8th and 18th weeks, implying that inflammation and immune response were enhanced, which may be related to the up-regulation of many antigen presentation molecules, chemokines, and cell surface molecules.

Rapid cell proliferation and growth were extensively observed during hepatocarcinogenesis (Xu et al., 2007). Cell proliferation contains DNA replication, cell cycle, nuclear and other organelles division, and cytoskeleton-based cytokinesis. In this study, the augmented 
expression of most of cell proliferation genes (i.e., cell cyclin genes ccna2, ccnb1, ccnb2, ccndl, and $c c n e 2$, cell division cycle genes $c d c 2 a$ and $c d c a 3$, cyclin-dependent kinase inhibitor $c d k n 1 a$ and $c d k n 2 a$, cell cycle transition genes gtsel, gspt2, and tpd52l1, kinesin family genes kif2c, chromosome assembly and disassembly genes asf $1 b$ and top $2 a$, spindle, centrosome and cytoskeleton-related genes bub1, spc24, spc25, racgap 1, hmmr, stmn1, tubb5, and anln, DNA damage response and DNA repair-related genes $u b e 2 c$ and $u h r f 1)$ was observed from $5 \mathrm{w}$ of the start-up period, and persisted during hepatocarcinogenesis with expression peak at $16 \mathrm{w}$. Gene synergy analysis showed that cell proliferation was increased during the entire occurrence and development of liver cancer, suggesting that above-mentioned genes may coordinate to promote cell proliferation and tissue growth in liver cancer.

It is generally believed that cell adhesion and migration are closely related to angiogenesis, tumor infiltration and metastasis in liver cancer (Li et al., 2007). Our study found integrin itgav was up-regulated at the 12th week of liver tumorigenesis, and laminin lamcl, matrix collagen col27a1, col4a5, col5a2, col6a3, and col8a1, tight junction protein cldn6, hyaluronan and proteoglycan link protein hapln3, coagulation-promoting gene $v w f$, neural cell adhesion molecule ncam 1, and tyrosine kinase receptor $d d r 2$ were increased at the 16th week. Moreover, tumor cell adhesion, migration-promoting gene fat 1 , cadherin $c d h 13$ and $p c d h 17$, lectin $\operatorname{clec} 7 a$ and its related protein lgals $3 b p$, selectin sele, immunoglobulin superfamily member thy1, laminin lama3, lama5, lamc1 and lamc2, matrix collagen colla2, col3a1, col4a1, col4a2, col4a5, col5a2, col6a2, col6a3, col8a1 and col27a1, integrin itgb6 and itgbl1, adhesion molecules $c d 9, c d 24$ and $c d 44$, tight junction protein jam3, cldn4, cldn6, cldn 7 and cldn8, connexin gjb5, transmembrane glycoprotein gpnmb, osteopontin spp1, connective tissue growth factor $\operatorname{ctg} f$, vascular endothelial cell adhesion molecule vcaml, vascular smooth muscle cell migration-promoting gene $m f g e 8$, melanoma cell adhesion molecule mcam, and tyrosine kinase receptor $d d r 1, \mathrm{G}$ protein-coupled receptor gpr56, signal transduction-related rhob and $r h o c$ were up-regulated mainly at $12-18 \mathrm{w}$ of liver cancer. Synergy value analysis showed that the synergy values of cell adhesion-, cell migration-related genes were higher than those in control, and it might correspond to high metabasis activity of tumor cell metabasis.

The formation of new vessels (angiogenesis) is an indispensable process related to liver cancer (Fernandez et al., 2009), including degradation of vascular basement membrane, vascular smooth muscle cell and endothelial cell proliferation, migration and adhesion, and vascular lumen formation of network structure (Carmeliet, 2005). Angiopoietin angpt1, vascular lumen formation-promoting gene cxcr4, and vascular permeability-enhancing gene nos 2 were up-regulated at the 16th week. Differentiation inhibitor Idl can activate the transcription of vascular endothelial growth factor (Ling et al., 2005). Transcription factor Klf5 induces the expression of some angiogenesis-related genes, such as PAI-1, iNOS and VEGF receptors (Aizawa et al., 2004). Many growth factors (Tgfb2, Ctgf and Pdgfa) and Ptk2b can promote the proliferation and migration of endothelial cells or smooth muscle cells through multiple signal pathways. Anxa2 and plasminogen activator Plat are involved in activating proteases and then promoting the degradation of extracellular matrix. Collagens Colla1, Colla2 and Col3a1 accelerate the development of blood vessel wall, and Spint1 induces the tube formation of blood vessel. Above-mentioned 12 genes were reinforced in expression at more than two time points of 12-18w. It was found that the synergy values of angiogenesis-related genes were greater than $E_{c}$ of the control in the 12 and 16th weeks, meaning that angiogenesis was increased, which may be highly related to the enhanced expression of above genes. 
The liver is an organ which undertakes the crucial function of metabolism of fundamental substances, such as carbohydrate, lipid, amino acid, protein, etc. External stimuli, such as drugs, poisons, etc. can cause hepatic changes in lipid metabolism, steroid metabolism, and homeostasis (Lockhart et al., 2003; Xu et al., 2005; Rosen et al., 2008). Liu et al. found glycolysis and fat metabolism had significant changes in the process of tumorigenesis, providing the essential materials for the growth, hyperplasia, and metastasis of tumor cells (Liu et al., 2009). In this study, phosphofructokinase 1 liver type ( $p f k l$ ) and pyruvate kinase muscle type ( $\mathrm{km} 2)$, two rate-limiting enzymes in glycolysis, were up-regulated in mRNA level at the 16th and 18th weeks. However, some important genes involved in glycolysis and gluconeogenesis, such as $p f k f b 4$ regulating the level of fructose 2, 6-bisphosphate, pyruvate kinase $p k l r$, sds (Ogawa et al., 2002) and g6pc promoting gluconeogenesis, onecut1 inducing gene expression of glucose kinase and glucose-6-phosphase (Lannoy et al., 2002; Beaudry et al., 2006), and nuclear transcription factors ppargcla, ppp1r3c and ppp1r3b, were downregulated, which possibly could explain why the synergy values of carbohydrate metabolismrelated genes were was significantly smaller than $E_{c}$ of the control at the period of 8-18w. As for lipid metabolism-related genes, mogat2 catalyzing monoacylglycerol into 1, 2-diacylglycerol, apoa5 and $l d l r$ promoting triacylglycerol transport and storage, $p c s k 9$ negatively regulating the storage of triacylglycerols (Lambert et al., 2006), cptla promoting fatty acid oxidation, elovl5 specific for very long chain fatty acid elongation, cyp7a1 in bile acid synthesis, nuclear receptor $n r 5 a 2$ inhibiting bile acid synthesis, $h s d 3 b 5$ and sult lel catalyzing cholesterol into sex hormone, akrlc18 and akrlcl in steroid hormone metabolism, and multiple genes within the pathway of cholesterol synthesis, including 3-hydroxy-3-methylglutaryl-Coenzyme A synthase 1 ( $h m g c s 1)$, isopentenyl-diphosphate delta isomerase (idil), sterol C4 methyl oxidaselike ( $s c 4 m o l)$, and $a b c g 8$ involved in cholesterol efflux, were attenuated with the expression bottom mainly at $12-18 \mathrm{w}$. It was not contrary to the fact that lipid metabolism was decreased at $5-18 \mathrm{w}$ of LC by gene synergy analysis. In addition, the $E_{t}$ of amino acid metabolism was significantly higher than in the control, which could be explained by the up-regulation of odc1, thnsll, and pycrl. Moreover, organic acid metabolism was shown by synergy analysis to be significantly lower during the entire tumoriogenesis, which may be caused by the down-regulation of a variety of fatty acid, amino acid metabolism-related genes. Therefore, lipid, amino acid and their derivative, organic acid metabolism were attenuated during the occurrence and development of liver cancer, suggesting that liver injury induced by carcinogenic agent had negative effect on the metabolism of fundamental substances (Jiang et al., 2007).

Briefly, Rat Genome 230 2.0 Array detection and gene synergy analysis showed that 909 genes, involved in 23 physiological activities, were associated with liver cancer occurrence. In the future, we will confirm the above results by using gene addition and RNA interference etc.

\section{ACKNOWLEDGMENTS}

Research supported by the National Basic Research 973 Pre-Research Program of China (\#2010CB534905).

\section{REFERENCES}

Aizawa K, Suzuki T, Kada N, Ishihara A, et al. (2004). Regulation of platelet-derived growth factor-A chain by Kruppel- 
like factor 5: new pathway of cooperative activation with nuclear factor-kappaB. J. Biol. Chem. 279: 70-76.

Beaudry JB, Pierreux CE, Hayhurst GP, Plumb-Rudewiez N, et al. (2006). Threshold levels of hepatocyte nuclear factor 6 (HNF-6) acting in synergy with HNF-4 and PGC-1alpha are required for time-specific gene expression during liver development. Mol. Cell Biol. 26: 6037-6046.

Carmeliet P (2005). Angiogenesis in life, disease and medicine. Nature 438: 932-936.

Chen X, Xu C, Zhang F and Ma J (2010). Comparative analysis of expression profiles of chemokines, chemokine receptors, and components of signaling pathways mediated by chemokines in eight cell types during rat liver regeneration. Genome 53: 608-618.

Coussens LM and Werb Z (2002). Inflammation and cancer. Nature 420: 860-867.

Edmondson HA and Steiner PE (1954). Primary carcinoma of the liver: a study of 100 cases among 48,900 necropsies. Cancer 7: 462-503.

Fernandez M, Semela D, Bruix J, Colle I, et al. (2009). Angiogenesis in liver disease. J. Hepatol. 50: 604-620.

Guo GB and Xu CS (2008). Expression profiles of the organic acid metabolism-associated genes during rat liver regeneration. Amino Acids 34: 597-604.

Jackson JR, Seed MP, Kircher CH, Willoughby DA, et al. (1997). The codependence of angiogenesis and chronic inflammation. FASEB J. 11: 457-465.

Jiang JT, Xu N, Zhang XY and Wu CP (2007). Lipids changes in liver cancer. J. Zhejiang Univ. Sci. B. 8: 398-409.

Lambert G, Jarnoux AL, Pineau T, Pape O, et al. (2006). Fasting induces hyperlipidemia in mice overexpressing proprotein convertase subtilisin kexin type 9: lack of modulation of very-low-density lipoprotein hepatic output by the lowdensity lipoprotein receptor. Endocrinology 147: 4985-4995.

Lannoy VJ, Decaux JF, Pierreux CE, Lemaigre FP, et al. (2002). Liver glucokinase gene expression is controlled by the onecut transcription factor hepatocyte nuclear factor-6. Diabetologia 45: 1136-1141.

Li H, Chen X, Zhang F, Ma J, et al. (2007). Expression patterns of the cell junction-associated genes during rat liver regeneration. J. Genet. Genomics 34: 892-908.

Ling MT, Lau TC, Zhou C, Chua CW, et al. (2005). Overexpression of Id-1 in prostate cancer cells promotes angiogenesis through the activation of vascular endothelial growth factor (VEGF). Carcinogenesis 26: 1668-1676.

Liu YF, Zha BS, Zhang HL, Zhu XJ, et al. (2009). Characteristic gene expression profiles in the progression from liver cirrhosis to carcinoma induced by diethylnitrosamine in a rat model. J. Exp. Clin. Cancer Res. 28: 107.

Lockhart AC, Tirona RG and Kim RB (2003). Pharmacogenetics of ATP-binding cassette transporters in cancer and chemotherapy. Mol. Cancer Ther. 2: 685-698.

McFadyen MC and Murray GI (2005). Cytochrome P450 1B1: a novel anticancer therapeutic target. Future Oncol. 1: 259-263.

McGuigan K (2006). Studying phenotypic evolution using multivariate quantitative genetics. Mol. Ecol. 15: 883-896.

Ogawa H, Gomi T, Takusagawa F, Masuda T, et al. (2002). Evidence for a dimeric structure of rat liver serine dehydratase. Int. J. Biochem. Cell Biol. 34: 533-543.

Rodriguez-Antona C and Ingelman-Sundberg M (2006). Cytochrome P450 pharmacogenetics and cancer. Oncogene 25: $1679-1691$.

Rosen MB, Lee JS, Ren H, Vallanat B, et al. (2008). Toxicogenomic dissection of the perfluorooctanoic acid transcript profile in mouse liver: evidence for the involvement of nuclear receptors PPAR alpha and CAR. Toxicol. Sci. 103: 46-56.

Scibior D, Skrzycki M, Podsiad M and Czeczot H (2008). Glutathione level and glutathione-dependent enzyme activities in blood serum of patients with gastrointestinal tract tumors. Clin. Biochem. 41: 852-858.

Vaclavikova R, Hubackova M, Stribrna-Sarmanova J, Kodet R, et al. (2007). RNA expression of cytochrome P450 in breast cancer patients. Anticancer Res. 27: 4443-4450.

Valles EG, Laughter AR, Dunn CS, Cannelle S, et al. (2003). Role of the peroxisome proliferator-activated receptor alpha in responses to diisononyl phthalate. Toxicology 191: 211-225.

Vera J and Wolkenhauer O (2008). A system biology approach to understand functional activity of cell communication systems. Methods Cell Biol. 90: 399-415.

Wang GP and Xu CS (2010). Reference gene selection for real-time RT-PCR in eight kinds of rat regenerating hepatic cells. Mol. Biotechnol. 46: 49-57.

Wang WB, Fan JM, Zhang XL, Xu J, et al. (2009). Serial expression analysis of liver regeneration-related genes in rat regenerating liver. Mol. Biotechnol. 43: 221-231.

Wurmbach E, Chen YB, Khitrov G, Zhang W, et al. (2007). Genome-wide molecular profiles of HCV-induced dysplasia and hepatocellular carcinoma. Hepatology 45: 938-947.

Xu CS and Chang CF (2008). Expression profiles of the genes associated with metabolism and transport of amino acids and their derivatives in rat liver regeneration. Amino Acids 34: 91-102. 
Xu CS, Zhang SB, Chen XG and Rahman S (2007). Correlation analysis of liver tumor-associated genes with liver regeneration. World J. Gastroenterol. 13: 3323-3332.

Xu Z, Chen L, Leung L, Yen TS, et al. (2005). Liver-specific inactivation of the Nrfl gene in adult mouse leads to nonalcoholic steatohepatitis and hepatic neoplasia. Proc. Natl. Acad. Sci. U. S. A. 102: 4120-4125.

Xue KX (2005). Molecular genetic and epigenetic mechanisms of hepatocarcinogenesis. Ai Zheng 24: 757-768. 